\title{
Identifying the mechanisms underlying the protective effect of tetramethylpyrazine against cisplatin-induced in vitro ototoxicity in HEI-OC1 auditory cells using gene expression profiling
}

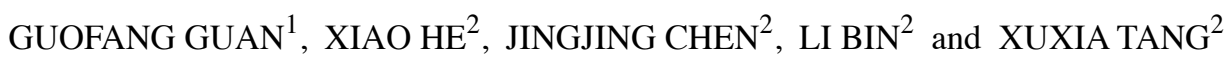 \\ ${ }^{1}$ Department of Otolaryngology, The Second Hospital of Jilin University, Changchun, Jilin 130041; \\ ${ }^{2}$ Department of Otolaryngology, The First Affiliated Hospital of Zhejiang Traditional Chinese Medical University, \\ Hangzhou, Zhejiang 310006, P.R. China
}

Received December 28, 2019; Accepted June 26, 2020

DOI: $10.3892 / \mathrm{mmr} .2020 .11631$

\begin{abstract}
Sensorineural hearing loss is prevalent in patients receiving cisplatin therapy. Tetramethylpyrazine (Tet) and tanshinone IIA (Tan IIA) have protective roles against hearing impairment or ototoxicity. The present study aimed to investigate the molecular mechanisms underlying cisplatin-induced ototoxicity and the protective effect of Tet and Tan IIA against it. House Ear Institute-Organ of Corti 1 auditory cells were treated with titrating doses of Tan IIA, Tet, and cisplatin. In a cell viability assay, cisplatin, Tan IIA and Tet had $\mathrm{IC}_{50}$ values of $42.89 \mu \mathrm{M}, 151.80$ and $1.04 \times 10^{3} \mathrm{mg} / \mathrm{l}$, respectively. Tan IIA augmented cisplatin-induced cytotoxicity. However, Tet concentrations $<75 \mathrm{mg} / \mathrm{l}$ attenuated cisplatin-induced cytotoxicity and apoptosis. Moreover, RNA sequencing analysis was carried out on auditory cells treated for $30 \mathrm{~h}$ with $30 \mu \mathrm{M}$ cisplatin alone for $48 \mathrm{~h}$ or combined with $37.5 \mathrm{mg} / \mathrm{l}$ Tet for $30 \mathrm{~h}$. Differentially expressed genes (DEGs) induced in these conditions were identified and examined using Gene Ontology and Kyoto Encyclopedia of Genes and Genomes pathway analysis. Cisplatin increased the expression of genes related to the p53 and FoxO pathways, such as Fas, p21/CDKN1A, and $\mathrm{Bcl}-2$ binding component 3 , but decreased the expression of insulin-like growth factor 1 (IGF1), as well as genes in the histone (Hist) 1 and Hist 2 clusters. Treatment with Tet downregulated $\mathrm{FOXO} 3$ and $\mathrm{Bcl}-2$ binding component 3 , and increased the expression of IGF1. Moreover, Tet upregulated genes associated with Wnt signaling, but not p53-related genes. Thus, the otoprotective properties of Tet might be mediated by
\end{abstract}

Correspondence to: Dr Xuxia Tang, Department of Otolaryngology, The First Affiliated Hospital of Zhejiang Traditional Chinese Medical University, 54 Youdian Road, Hangzhou, Zhejiang 310006, P.R. China

E-mail: maggietangzj@163.com

Key words: sensorineural hearing loss, ototoxicity, cisplatin, tanshinone, tetramethylpyrazine, transcriptome activation of Wnt and IGF1 signaling, and inhibition of FoxO signaling.

\section{Introduction}

Cisplatin is a radiation sensitizer and cytotoxic agent commonly used in cancer therapy. Cisplatin-induced sensorineural hearing loss (SHL) is especially prevalent among patients with brain tumors, head and neck cancer, and nasopharyngeal carcinoma (1-3). The incidence of lowand high-frequency SHL ranges from $10-97 \%$ in patients who receive cisplatin-based chemoradiation (2-4). Despite recent advances in treatments for cisplatin-induced SHL, the prevalence of cisplatin-induced cytotoxicity and damage in cochlear hair cells remains high (3). The primary cisplatin accumulation site is the cochlea, where cisplatin can be retained for months, or even years (1). As a result, the time from cisplatin chemotherapy to SHL onset also ranges from months to years (5).

Cisplatin-induced SHL is mechanistically related to enhanced apoptosis and DNA damage (6,7). It has also been reported that reactive oxygen species (ROS), as well as Wnt and p53 signaling pathways, are activated in the cochlea following cisplatin therapy (8-10). Wnt activation protects against cytotoxicity in cochlear hair cells (9). Moreover, abnormal expression of genes and non-coding RNAs, such as microRNAs, is also associated with SHL (11).

Several drugs with antagonistic effects against cisplatininduced cytotoxicity, DNA damage, and apoptosis in cochlear hair cells might represent potential treatment strategies for cisplatin-induced ototoxicity (10,12-14). For instance, tetramethylpyrazine (Tet) and tanshinone IIA (Tan IIA) can protect against hearing impairment and ototoxicity induced by aminoglycoside antibiotics, cisplatin, and radiation (15-17). Tet can also decrease caspase-3 expression in spiral ganglion and apoptosis in guinea pig cochlea $(15,17)$. Tan IIA has been reported to protect House Ear Institute-Organ of Corti 1 (HEI-OC1) auditory cells from cisplatin-induced ototoxicity and may synergize with cisplatin, enhancing cytotoxicity against cancer cells by promoting apoptosis and cell cycle arrest at the $\mathrm{S}$ phase (18). 
The molecular mechanisms underlying the protective effects of Tet and Tan IIA against cisplatin-induced ototoxicity are poorly understood. Therefore, the aim of the present study was to determine the mechanistic basis of this otoprotective effect in vitro. HEI-OC1 auditory cells were exposed to cisplatin and treated with Tet or Tan IIA. Tet, but not Tan IIA, reversed the inhibitory effect of cisplatin on HEU-OC1 viability. The underlying molecular mechanisms were investigated using high-throughput, next-generation sequencing, and bioinformatics analysis. The findings of the present study provided insight into cisplatin-induced ototoxicity in vitro and the Tet-mediated protective effects against it.

\section{Materials and methods}

Cell culture. HEI-OC1 auditory cell line was a gift from Professor Federico Kalinec (David Geffen School of Medicine at UCLA, CA, USA) and maintained at $32^{\circ} \mathrm{C}$ in $10 \% \mathrm{CO}_{2}$ in high-glucose Dulbecco's modified Eagle's medium (DMEM; HyClone; GE Healthcare Life Sciences) supplemented with $2 \mathrm{mM}$ L-glutamine, $1 \mathrm{mM}$ sodium pyruvate and $10 \%$ fetal bovine serum (FBS; HyClone).

Cell treatments. HEI-OC1 auditory cells were separately treated for $48 \mathrm{~h}$ at $32^{\circ} \mathrm{C}$ in $10 \% \mathrm{CO}_{2}$ with Tan IIA $(3,9,27,81$, 243 or $729 \mathrm{mg} / \mathrm{l}$; Shanghai Yuanye Biotechnology Co., Ltd.), Tet $\left(125,250,500,1 \times 10^{3}, 2 \times 10^{3}, 410^{3}, 8 \times 10^{3}\right.$ or $1.60 \times 10^{4} \mathrm{mg} / \mathrm{l}$; Shanghai Aladdin Bio-Chem Technology Co., Ltd.) or cisplatin $(5,10,20,40,80$ and $160 \mu \mathrm{M}$; Sigma-Aldrich; Merck KGaA). In a separate experiment, the cells were treated for $30 \mathrm{~h}$ with $30 \mu \mathrm{M}$ cisplatin combined either with Tan IIA $(0.2,0.5,1.0$, or $1.5 \mathrm{mg} / \mathrm{l})$ or with Tet $(37.5,75,125$ or $250 \mathrm{mg} / \mathrm{l})$ at $32^{\circ} \mathrm{C}$ in $10 \%$ $\mathrm{CO}_{2}$. The assays were carried out in triplicate wells.

Cell viability assay. Cells were seeded into 96-well plates (Corning, Inc.) at a density of $5 \times 10^{4}$ cells $/ \mathrm{ml}$ and maintained in high-glucose DMEM for $24 \mathrm{~h}$. The culture medium was then replaced with fresh medium supplemented with Tan IIA, Tet, cisplatin or combinations as aforementioned. Cell viability was then assessed using Cell Counting Kit-8 (MedChemExpress) according to the manufacturer's instructions. The optical density was read at $450 \mathrm{~nm}$ using a microplate reader (Bio-Rad Laboratories, Inc.).

Cell apoptosis assay. Cell apoptosis was measured using Annexin V-fluorescein isothiocyanate (FITC) and propidium iodide (PI; Beyotime Institute of Biotechnology) staining. Cells $\left(5 \times 10^{4}\right.$ cells/well) were plated in 6 -well plates, then treated in triplicate with cisplatin for $48 \mathrm{~h}$ or with cisplatin and Tet for $30 \mathrm{~h}$ at $32^{\circ} \mathrm{C}$ in $10 \% \mathrm{CO}_{2}$. Following incubation, cells were collected by centrifugation at $4^{\circ} \mathrm{C}$ and $1,500 \mathrm{x}$ for $5 \mathrm{~min}$, then resuspended in $1 \mathrm{X}$ binding buffer. The samples were then stained with $5 \mu \mathrm{l}$ of Annexin-V-FITC solution and $5 \mu \mathrm{l}$ of PI at $4^{\circ} \mathrm{C}$ for $10-15 \mathrm{~min}$ in dark. The data were acquired using a BD FACSCanto-II flow cytometer (BD Biosciences) and analyzed using an Olympus BX51 fluorescence microscope (Olympus Optical, Tokyo, Japan).

Western blot analysis. Proteins were extracted using RIPA lysis buffer (Beyotime Institute of Biotechnology) according to the manufacturer's instructions. Protein concentration was determined using a Bradford protein assay kit (Thermo Fisher Scientific Inc.). The samples $(20 \mu \mathrm{g})$ were resolved by SDS-PAGE on $10 \%$ gels (Shanghai Sangong Pharmaceutical Co., Ltd.), then transferred to PVDF membranes (EMD Millipore). The membranes were then blocked with 5\% nonfat milk (Beyotime Institute of Biotechnology) at room temperature for $1 \mathrm{~h}$. The membranes were first incubated with target-specific primary antibodies, including anti-P21 (1:1,000; cat. no. ab188224; Abcam), anti-p16-INK4A (1:1,000; cat. no. ab211542; Abcam), anti-FOXO3 (1:1,500; cat. no. 2497S; Cell Signaling Technology, Inc.), anti-caspase 3 (1:1,000; cat. no. ab13847; Abcam), anti-Fas (1:2,000; cat. no. ab216991; Abcam), anti-Wnt receptor frizzled 6 (FZD6; 1:2,000; cat. no. DF4930; Affinity Biosciences), anti-transcriptional repressor transcription factor 7-like 1 (TCF7L1; 1:1,500; cat. no. ab86175; Abcam), anti-wingless-type MMTV integration site family, member 2 (WNT2; 1:800; cat. no. ab109222; Abcam), anti-insulin-like growth factor 1 (IGF1; 1:1,500; cat. no. ab182408; Abcam), anti-SERPINE1 (1:1500; cat. no. DF13553; Affinity Biosciences) and anti-GAPDH (1:10,000; cat. no. KC-5G5; Shanghai Kangcheng Biotechnology Co. Ltd.) at $4^{\circ} \mathrm{C}$ overnight. The membranes were then incubated with horseradish peroxidase-conjugated secondary antibody (anti-rabbit IgG; 1:20,000; cat. no. ba1054; Boster Biological Technology, Ltd.) at room temperature for $40 \mathrm{~min}$. Lastly, protein bands were visualized using an ECL kit (EMD Millipore).

RNA extraction and whole transcriptome sequencing. Total RNA was extracted using the TRIzol ${ }^{\circledR}$ reagent (Invitrogen; Thermo Fisher Scientific, Inc.) at 48 and $30 \mathrm{~h}$ post-treatment. RNA concentration and purity were determined using a NanoDrop 2000 spectrophotometer (Thermo Fisher Scientific, Inc.) and an Agilent 2100 Bioanalyzer (Agilent Technologies Inc.). RNA samples with an RNA integrity number (RIN) value of $>$ eight were used for library preparation. RNA was fragmented, reverse transcribed to the first-strand cDNA using reverse transcriptase (Invitrogen; Thermo Fisher Scientific, Inc.) and random hexamers (Sangon Biotech Co., Ltd.), then synthesized to double-stranded DNA using dNTPs (Invitrogen; Thermo Fisher Scientific, Inc.) at $37^{\circ} \mathrm{C}$ for $15 \mathrm{~min}$ and at $98^{\circ} \mathrm{C}$ for $5 \mathrm{~min}$. The DNA sequencing libraries were prepared using a TruSeq ${ }^{\mathrm{TM}}$ RNA Sample Preparation Kit (version 2; Illumina, cat. nos. RS-122-2001 RS-122-2002) following the protocols including DNA fragment end repair, adenylating, adapter ligation, and fragment amplification. After verifying the library quality using the Qubit2.0 (Thermo Fisher Scientific, Inc.), Agilent 2100 (Agilent Technologies Inc.), and qPCR, sequencing (loading concentration $3 \mathrm{nM} / \mu \mathrm{l}$ ) was carried out using a V1 sequencing kit (Illumina, Inc.) on an Illumina HiSeq 4000 sequencing platform (paired-end; $150 \mathrm{bp}$; Illumina, Inc.).

Data processing. Base calling of the original sequencing image data and fastq file extraction were carried out using Illumina CASAVA software (version 1.8.2; Illumina, Inc.). The quality of raw data was checked using the FastQC program (version 0.11.5; http://www.bioinformatics.babraham. 

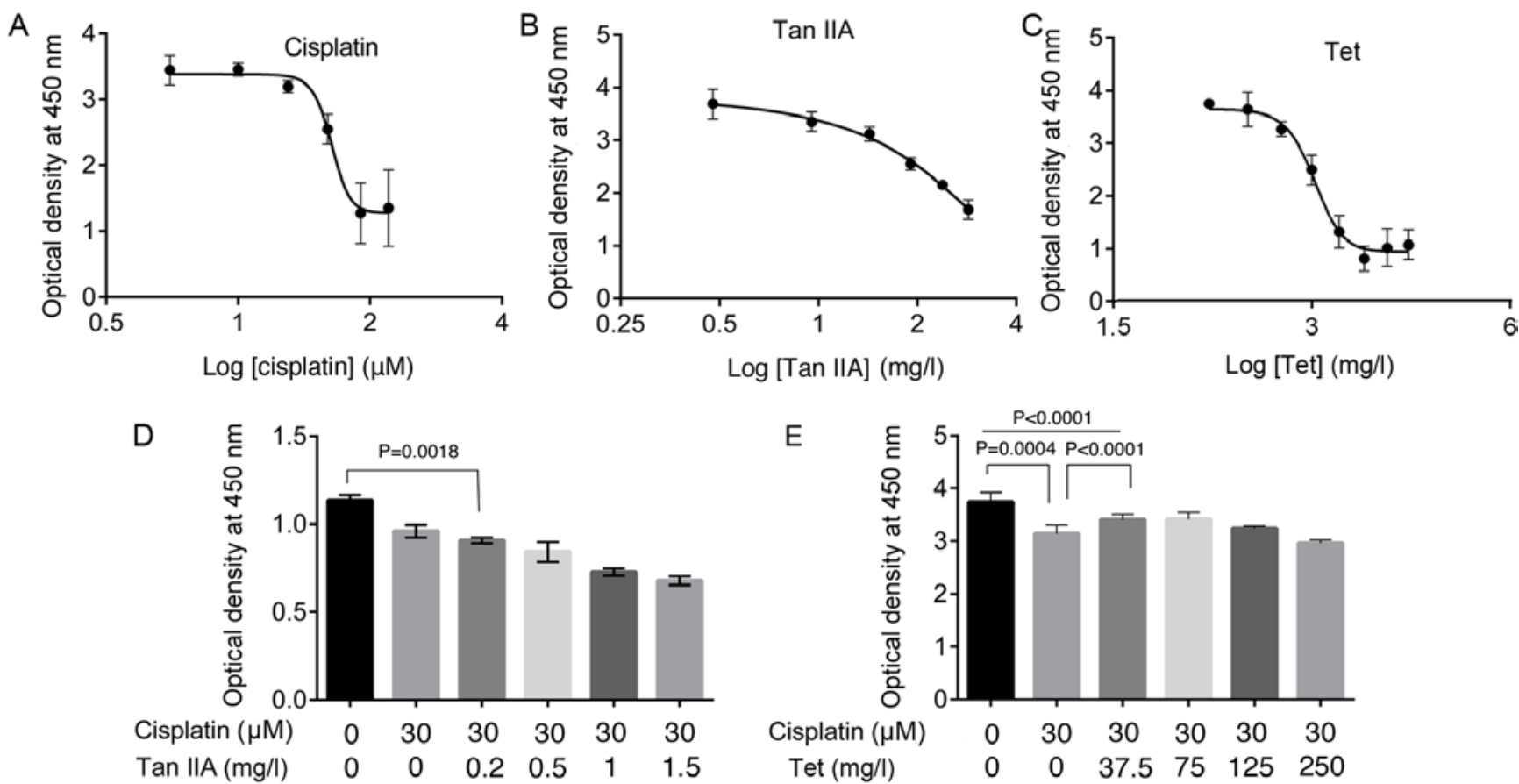

Figure 1. Cisplatin, Tan IIA and Tet inhibit the viability of HEI-OC1 cells. (A-C) Dose-dependent inhibition of viability of HEI-OC1 cells following 48-h treatment with cisplatin, Tan IIA and Tet. HEI-OC1 cell viability following 30-h treatment with (D) Cisplatin + Tan IIA or (E) Cisplatin + Tet. Differences among groups in panel D and E were analyzed using one-way ANOVA followed by Tukey's post hoc test. Tan IIA, tanshinone IIA; Tet, tetramethylpyrazine.

ac.uk/projects/fastqc/). After adaptor trimming and removal of duplicated and low-quality reads (unknown base sequence $>10 \%$, and $>50 \%$ of the read consisted of reads with Phred scores of $\leq 3$ ) using Trimmomatic (version 0.30; http://www. usadellab.org $/ \mathrm{cms} /$ ?page=trimmomatic), the clean reads were mapped to the ENSEMBL Mus musculus GRCm38. p6 reference genome (http://www.ensembl.org/) with annotation version GRCm38.97 using the TopHat 2 software (http://ccb.jhu.edu/software/tophat/index.shtml).

Transcript assembly and quantification was performed using the Cufflinks software (version 2.2.1; http://cufflinks. cbcb.umd.edu/) by calculating the expected number of fragments per kilobase of exon model per million reads mapped (FPKM) values in each sample. Differentially expressed genes (DEGs) between groups were identified using the edgeR statistical software package (Bioconductor; http://www. bioconductor.org/) according to the criteria of FDR $<0.05$ and $\left|\log _{2}(\mathrm{FC})\right| \geq 1$, where FDR is the false discovery rate and FC is the fold change.

Enrichment analysis. Gene Ontology (GO; http://www.geneontology.org/) biological processes and Kyoto Encyclopedia of Genes and Genomes (KEGG) pathways associated with the DEGs were identified from the Database for Annotation, Visualization, and Integrated Discovery (DAVID; version 6.7; http://david.ncifcrf.gov/). $\mathrm{P}<0.05$ was used to identify statistically significant terms.

Protein-protein interaction (PPI) network analysis. The interaction between DEGs was predicted and extracted from STRING (version 10; www.string-db.org). PPI networks were constructed and visualized using Cytoscape (version 2.8; http://www.cytoscape.org/).
Statistical analysis. Quantitative data are presented as the mean \pm SD of triplicates. Statistical analysis was carried out using GraphPad Prism software (version 6; GraphPad Software, Inc.). Multigroup comparisons were analyzed using one-way ANOVA followed by Tukey's post hoc test. The $\mathrm{IC}_{50}$ values of Tan IIA, Tet, and cisplatin were calculated using nonlinear regression. $\mathrm{P}<0.05$ was considered to indicate a statistically significant difference.

\section{Results}

Cisplatin, Tan IIA, and Tet inhibit HEI-OCl auditory cell viability. Treatment with cisplatin, Tan IIA, and Tet for $48 \mathrm{~h}$ inhibited the viability of HEI-OC1 auditory cells in a dose-dependent manner (Fig. 1A-C), with $\mathrm{IC}_{50}$ values of $42.89 \mu \mathrm{M}, 151.80$ and $1.04 \times 10^{3} \mathrm{mg} / \mathrm{l}$, respectively.

Low Tet concentration prevents cisplatin-induced cytotoxicity in HEI-OCl auditory cells. To investigate whether Tan IIA and Tet administration could suppress the inhibitory effect of cisplatin on HEI-OC1 auditory cell viability, cells were treated with $30 \mu \mathrm{M}$ cisplatin combined with Tan IIA $(0.2$, $0.5,1.0$ and $1.5 \mathrm{mg} / \mathrm{l})$ or Tet $(37.5,75,125$ and $250 \mathrm{mg} / \mathrm{l})$ for $30 \mathrm{~h}$. To minimize drug-related cytotoxicity, the selected concentrations were $<\mathrm{IC}_{50}$ values. The addition of Tan IIA at concentrations $<1.5 \mathrm{mg} / \mathrm{l}$ augmented the effect of cisplatin and further inhibited viability significantly compared with cisplatin alone ( $\mathrm{P}=0.0018$, Fig. 1D). However, at concentrations of 37.5 and $75 \mathrm{mg} / \mathrm{l}$ Tet significantly increased viability, compared with cisplatin alone $(\mathrm{P}<0.0001$, Fig. $1 \mathrm{E})$.

The percentage of apoptotic HEI-OC1 auditory cells was significantly increased following cisplatin treatment, compared with control cells $(10.27 \pm 0.64 \%$ and $3.11 \pm 0.17 \%$ in the second 

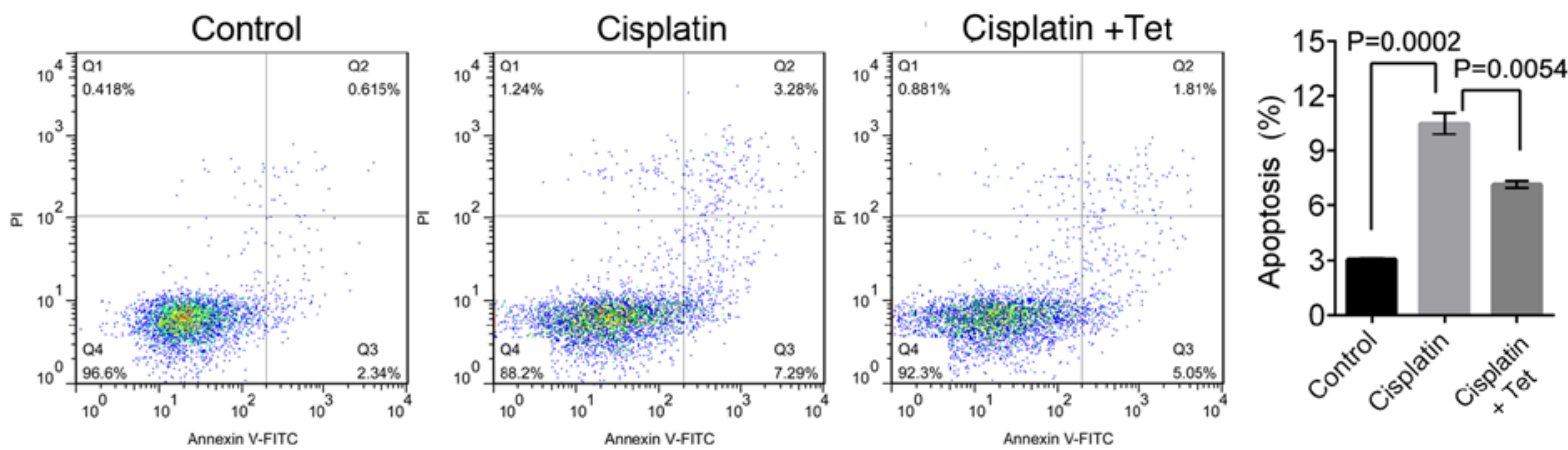

Figure 2. Apoptosis of HEI-OC1 cells. HEI-OC1 cells were treated with cisplatin alone or combined with Tet. Differences between groups were analyzed using one-way ANOVA followed by Tukey's post hoc test. PI, propidium iodide; FITC, fluorescein isothiocyanate; Tet, tetramethylpyrazine.
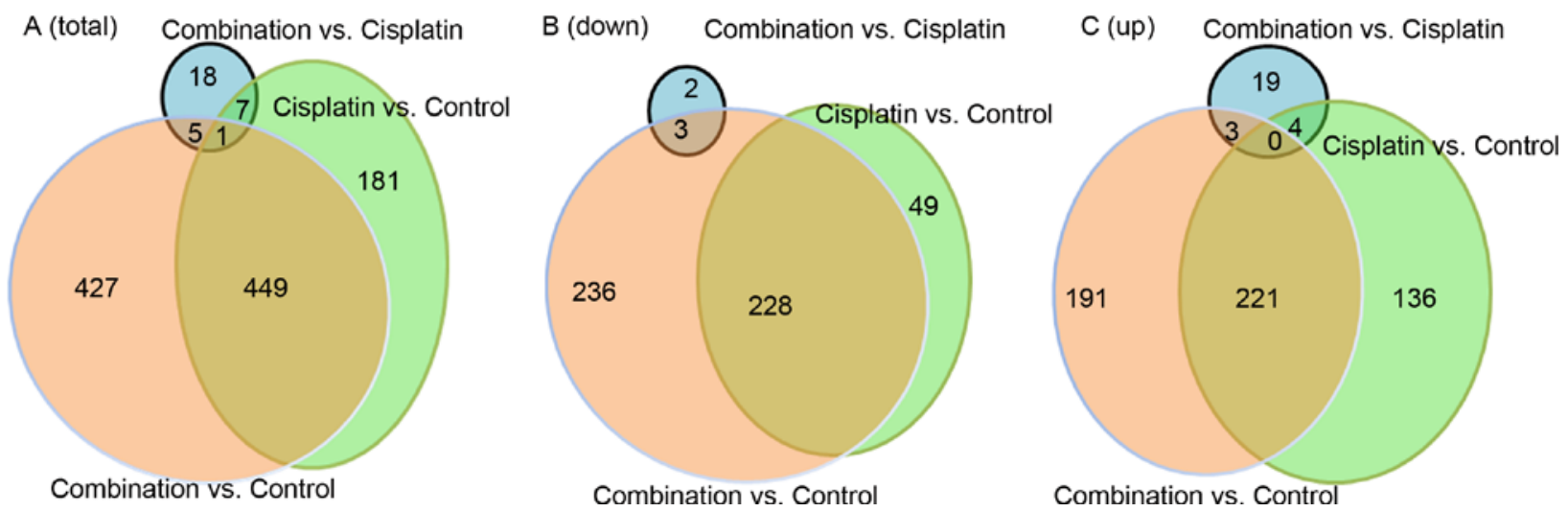

Figure 3. The Venn diagram of DEG in HEI-OC1 cells. (A-C) Venn diagram of the (A) total, (B) downregulated, and (C) upregulated DEGs identified following treatment with cisplatin alone or combined with Tet. DEG, differentially expressed gene.

(upper right) and third (lower right) quadrants, respectively; $\mathrm{P}=0.0002$; Fig. 2). However, co-treatment with cisplatin and Tet reduced the apoptosis rate to $7.18 \pm 0.33 \%(\mathrm{P}=0.0054)$. Collectively, these results indicated that low concentrations of Tet could protect HEI-OC1 cells against cisplatin-induced cytotoxicity.

Summary of Illumina sequencing. To examine the molecular mechanisms associated with the otoprotective properties of Tet, RNA sequencing (RNA-seq) analysis was carried out on HEI-OC1 auditory cells treated with $30 \mu \mathrm{M}$ cisplatin alone or combined with $37.5 \mathrm{mg} / 1$ Tet. Illumina sequencing produced a total of 518.83 million raw reads, corresponding to 510.65 million clean reads and $74.31 \mathrm{Gbp}$ (Table SI). The average GC content was $50.26 \%$, while the average frequency of reads $>$ Q30 was $95.91 \%$. Transcriptome assembly generated $1,455,306$ transcripts. In comparison with control cells, 638 DEGs were identified following cisplatin treatment, including 361 upregulated genes and 277 downregulated genes (Fig. 3A-C). Moreover, 882 DEGs were observed in cells treated with a combination of cisplatin and Tet, including 415 upregulated and 467 downregulated genes (Fig. 3B and C). Thus, relative to untreated cells, the combination of cisplatin and Tet induced more DEGs than cisplatin alone. A total of 449 DEGs were shared between the two datasets, including 221 upregulated and 228 downregulated DEGs (Fig. 3B and C). In comparison with cisplatin alone, the combination with Tet (37.5 mg/l) only induced 31 DEGs, including 26 upregulated and 5 downregulated DEGs). In total, 1,088 DEGs were identified, including 626 non-overlapping DEGs (Fig. 3A-C).

Summary and annotation of cisplatin-induced DEGs. To examine the molecular mechanisms underlying cisplatin-induced cytotoxicity, the biological processes and pathways associated with the identified DEGs were examined using GO and KEGG analysis. GO functional enrichment analysis indicated that downregulated DEGs, such as histone (Hist)1 and Hist2 gene clusters (Fig. 4), were associated with biological processes related to 'DNA replication-dependent nucleosome assembly', 'nucleosome assembly', and 'DNA-templated transcription, initiation' (Table I). Other downregulated DEGs were also associated with biological processes, including 'negative regulation of apoptotic process' (thrombospondin1, THBS1; TWIST2; insulin-1 receptor antagonist gene, IL1RN; IGF1) and regulation of cell migration (IL1RN; SERPINE1; IGF binding protein 5, IGFBP5).

Moreover, the downregulated DEGs identified following cisplatin treatment were also associated with several KEGG pathways. Genes in the Hist 1 and Hist 2 clusters were associated with 'Systemic lupus erythematosus', 'Alcoholism' and 'Viral carcinogenesis' (Table II). IGF1 and THBS1 were involved in 'PI3K-Akt signaling pathway', 'Rap1 signaling pathway', and 'HIF-1 signaling pathway'.

Notably, the upregulated DEGs induced by cisplatin in HEI-OC1 auditory cells were significantly associated with autophagy (autophagy-related gene 12, ATG12; ATG9B; 


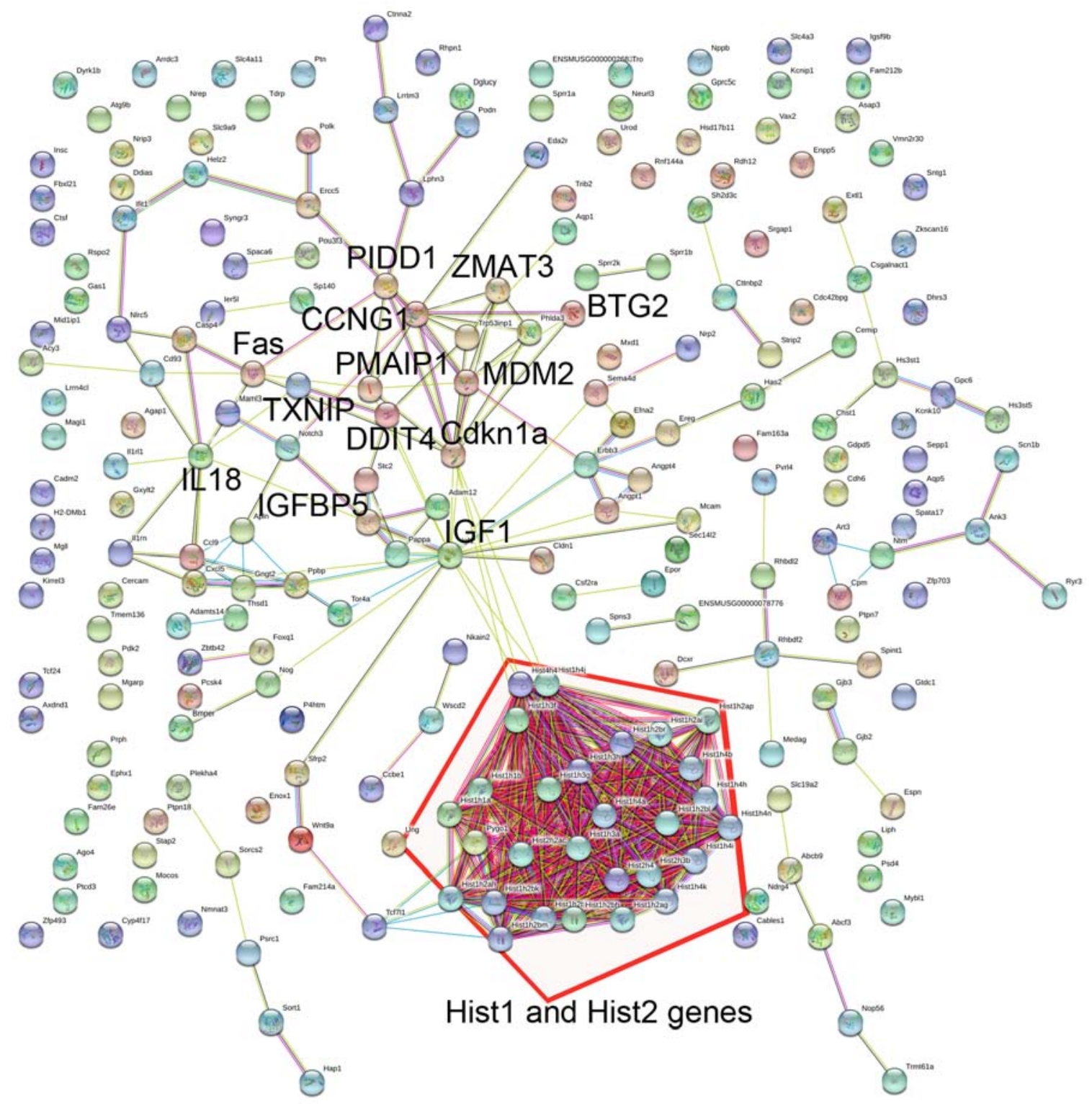

Figure 4. Protein-protein interaction network of the identified DEGs. The protein-protein interaction network consists of 364 nodes (gene products) and 1,268 lines (interaction pairs). DEG, differentially expressed gene.

ATG2A), apoptosis-associated processes, response to DNA damage and cell cycle arrest. These genes included phorbol-12-myristate-13-acetate-induced protein 1 (PMAIP1), Bcl-2 binding component 3 (BBC3), zinc finger matrin-type 3 (ZMAT3), p53-induced death domain protein 1 (PIDD1), B-cell translocation gene protein 2 (BTG2), thioredoxin-interacting protein (TNXIP), DNA damage induced apoptosis suppressor (DDIAS), cycle-dependent kinase inhibitor 1A (CDKN1A), transformation related protein 53-induced nuclear protein 1 (TRP53INP1), FOXO3, and Fas (Table I). These DEGs interacted closely (Fig. 4) and some (including CDKN1A, BBC3, ZMAT3, PMAIP1, FAS, PIDD1, and FOXO3) were significantly associated with 'p53 signaling pathway' and 'FoxO signaling pathway' (Table II).

Common effect of Tet and cisplatin on transcriptome expression profiles. As indicated in Fig. 3, 450 DEGs were shared between the two treatments. The shared DEGs included Fas, PMAIP1, ATG12, CDKN1A, and ZMAT3, which were upregulated, and THBS1 and SERPINE1, which were downregulated (Fig. 5A-D). Enrichment analysis showed these shared genes enriched in similar functional categories and KEGG pathways as DEGs induced by cisplatin alone (Tables III and IV). The upregulated genes including THBS1, CDKN1A, Fas, PMAIP1, TXNIP, and ZMAT3 were associated with biological processes, such as 'programmed cell death' and 'cell cycle' (Table III). Genes including CDKN1A, Fas, PMAIP1, TXNIP, and ZMAT3 and pathways including 'p53 signaling pathway' and/or 'Apoptosis' (Table IV). The downregulated genes including the histone genes, endothelin 1 (EDN1), suppressor of cytokine signaling 3 (SOCS3), and insulin receptor substrate 1 (IRS1) were associated with biological processes, such as 'nucleosome assembly' and 'regulation of phosphate metabolic process' (Table III). The downregulated DEGs including THBS1, collagen type III alpha 1 chain (COL3A1), and platelet derived growth factor subunit $\mathrm{B}$ (PDGFB) were involved in 'ECM-receptor interaction' and 'Focal adhesion' (Table IV). 
Table I. Top 15 GO biological processes associated with the differentially expressed genes induced by cisplatin vs. control.

A, Downregulated genes

\begin{tabular}{|c|c|c|c|}
\hline Term & Count & P-value & Gene name \\
\hline GO:0006334, nucleosome assembly & 24 & $3.3010^{-22}$ & $\begin{array}{l}\text { HIST2H3B, HIST1H2BB, HIST1H1C, HIST1H1B, H1F0, } \\
\text { ANP32B, H3F3B, HIST1H3F, HIST1H4I, HIST1H3G, etc. }\end{array}$ \\
\hline $\begin{array}{l}\text { GO:0000183, chromatin silencing } \\
\text { at rDNA }\end{array}$ & 16 & $2.22 \times 10^{-16}$ & $\begin{array}{l}\text { HIST2H3B, HIST1H2BB, HIST1H1C, HIST1H1B, BEND3, } \\
\text { POLR1B, HIST2H4, SAP30, UBTF, HIST1H4A, etc. }\end{array}$ \\
\hline $\begin{array}{l}\text { GO:0032776, DNA methylation on } \\
\text { cytosine }\end{array}$ & 12 & $1.37 \times 10^{-13}$ & $\begin{array}{l}\text { HIST2H3B, HIST4H4, HIST1H4A, HIST1H4B, HIST1H3A } \\
\text { H3F3B, HIST1H3F, HIST1H4I, HIST1H3G, HIST1H4J, etc. }\end{array}$ \\
\hline $\begin{array}{l}\text { GO: } 0045815 \text {, positive regulation of } \\
\text { gene expression, epigenetic }\end{array}$ & 12 & $2.03 \times 10^{-13}$ & $\begin{array}{l}\text { HIST2H3B, HIST4H4, HIST1H4A, HIST1H4B, HIST1H3A } \\
\text { H3F3B, HIST1H3F, HIST1H4I, HIST1H3G, HIST1H4J, etc. }\end{array}$ \\
\hline $\begin{array}{l}\text { GO:0006335, DNA replication- } \\
\text { dependent nucleosome assembly }\end{array}$ & 11 & $7.75 \times 10^{-12}$ & $\begin{array}{l}\text { HIST2H3B, HIST4H4, HIST1H4A, HIST1H4B, HIST1H3A } \\
\text { HIST1H3F, HIST1H4I, HIST1H3G, HIST1H4J, } \\
\text { HIST1H4H, etc. }\end{array}$ \\
\hline $\begin{array}{l}\text { GO:0051290, protein } \\
\text { heterotetramerization }\end{array}$ & 11 & $3.70 \times 10^{-10}$ & $\begin{array}{l}\text { HIST2H3B, HIST4H4, HIST1H4A, HIST1H4B, HIST1H3A } \\
\text { HIST1H3F, HIST1H4I, HIST1H3G, HIST1H4J, } \\
\text { HIST1H4H, etc. }\end{array}$ \\
\hline $\begin{array}{l}\text { GO:0006336, DNA replication-inde } \\
\text { pendent nucleosome assembly }\end{array}$ & 8 & $2.19 \times 10^{-8}$ & $\begin{array}{l}\text { HIST4H4, HIST1H4A, HIST1H4B, H3F3B, HIST1H4I, } \\
\text { HIST1H4J, HIST1H4H, HIST2H4 }\end{array}$ \\
\hline $\begin{array}{l}\text { GO:0045653, negative regulation of } \\
\text { megakaryocyte differentiation }\end{array}$ & 7 & $4.84 \times 10^{-8}$ & $\begin{array}{l}\text { HIST4H4, HIST1H4A, HIST1H4B, HIST1H4I, HIST1H4J, } \\
\text { HIST1H4H, HIST2H4 }\end{array}$ \\
\hline $\begin{array}{l}\text { GO:0001649, osteoblast } \\
\text { differentiation }\end{array}$ & 12 & $2.46 \times 10^{-7}$ & $\begin{array}{l}\text { NOG, IGF1, COL6A1, TWIST2, IGFBP5, SPP1, FHL2, } \\
\text { GJA1, H3F3B, MYBBP1A, etc. }\end{array}$ \\
\hline $\begin{array}{l}\text { GO:0043066, negative regulation of } \\
\text { apoptotic process }\end{array}$ & 25 & $3.61 \times 10^{-7}$ & $\begin{array}{l}\text { TWIST2, THBS1, IL1RN, IGF1, GAS1, SERPINB9, } \\
\text { PDGFRB, YBX3, FHL2, AQP1, etc. }\end{array}$ \\
\hline $\begin{array}{l}\text { GO:0001701, in utero embryonic } \\
\text { development }\end{array}$ & 17 & $1.89 \times 10^{-6}$ & $\begin{array}{l}\text { NOG, EDN1, YBX3, TPM1, HES1, PDGFRB, ANGPT1, } \\
\text { PTCH1, GJB3, GJA1, etc. }\end{array}$ \\
\hline GO:0030324, lung development & 11 & $4.89 \times 10^{-6}$ & $\begin{array}{l}\text { HES1, MIR92-1, MIR17, MIR18, CCBE1, MIR20A, PTN, } \\
\text { IGF1, LOX, MIR19B-1, etc. }\end{array}$ \\
\hline $\begin{array}{l}\text { GO:0006352, DNA-templated } \\
\text { transcription, initiation }\end{array}$ & 7 & $7.32 \times 10^{-6}$ & $\begin{array}{l}\text { HIST4H4, HIST1H4A, HIST1H4B, HIST1H4I, HIST1H4J, } \\
\text { HIST1H4H, HIST2H4 }\end{array}$ \\
\hline $\begin{array}{l}\text { GO:0030336, negative regulation of } \\
\text { cell migration }\end{array}$ & 10 & $9.64 \times 10^{-6}$ & $\begin{array}{l}\text { NOG, PDGFB, SFRP2, IL1RN, SERPINE1, PTN, CNN2, } \\
\text { TPM1, SRGAP1, IGFBP5 }\end{array}$ \\
\hline $\begin{array}{l}\text { GO: } 0030335, \text { positive regulation of } \\
\text { cell migration }\end{array}$ & 13 & $1.38 \times 10^{-5}$ & $\begin{array}{l}\text { PDGFB, EDN1, IGF1, AQP1, CXCL12, THBS1, IRS1, } \\
\text { CEMIP, SEMA3C, PDGFRB, etc. }\end{array}$ \\
\hline
\end{tabular}

B, Upregulated genes

\begin{tabular}{|c|c|c|c|}
\hline Term & Count & P-value & Gene name \\
\hline GO:0006914, autophagy & 9 & $1.97 \times 10^{-4}$ & $\begin{array}{l}\text { TRP53INP1, ATG9B, ATG12, ATG2A, SESN2, HAP1, } \\
\text { ABARAPL1, OPTN, ARSA }\end{array}$ \\
\hline GO:0006915, apoptotic process & 18 & $2.35 \times 10^{-4}$ & $\begin{array}{l}\text { ZMAT3, FOXO3, PMAIP1, TRP53INP1, BBC3, PIDD1, } \\
\text { FAS, DDIAS, DDIT4, PHLDA3, etc. }\end{array}$ \\
\hline $\begin{array}{l}\text { GO:0072332, intrinsic apoptotic } \\
\text { signaling pathway by p53 class } \\
\text { mediator }\end{array}$ & 5 & $3.76 \times 10^{-4}$ & PDK2, BBC3, ZMAT3, EDA2R, PMAIP1 \\
\hline $\begin{array}{l}\text { GO:0042771, intrinsic apoptotic } \\
\text { signaling pathway in response to DNA } \\
\text { damage by p } 53 \text { class mediator }\end{array}$ & 5 & $3.76 \times 10^{-4}$ & CDKN1A, BBC3, PMAIP1, PHLDA3, DDIT4 \\
\hline $\begin{array}{l}\text { GO:0006919, activation of } \\
\text { cysteine-type endopeptidase activity } \\
\text { involved in apoptotic process }\end{array}$ & 6 & $9.12 \times 10^{-4}$ & TNFRSF10B, NOD1, BBC3, PMAIP1, APAF1, PIDD1 \\
\hline $\begin{array}{l}\text { GO:0006974, cellular response to } \\
\text { DNA damage stimulus }\end{array}$ & 14 & $9.13 \times 10^{-4}$ & $\begin{array}{l}\text { CDKN1A, BBC3, TRP53INP1, PIDD1, PMAIP1, DDIAS, } \\
\text { BTG2, ZMAT3, ERCC5, POLK, etc. }\end{array}$ \\
\hline
\end{tabular}


Table I. Continued.

B, Upregulated genes

\begin{tabular}{lccl}
\hline Term & Count & P-value & \\
\hline $\begin{array}{l}\text { GO:0000045, autophagosome } \\
\text { assembly }\end{array}$ & 5 & $1.45 \times 10^{-3}$ & ATG9B, GABARAPL1, ATG12, ATG2A, TRP53INP1 \\
GO:0048536, spleen development & 5 & $1.7 \times 10^{-3}$ & RIPK3, NFKB2, FAS, CTC1, RC3H1 \\
GO:0007050, cell cycle arrest & 6 & $2.13 \times 10^{-3}$ & CDKN1A, AK1, RASSF1, WDR6, TRP53INP1, DDIAS \\
GO:0016236, macroautophagy & 4 & $2.34 \times 10^{-3}$ & ATG12, NBR1, OPTN, ZFYVE1 \\
GO:0051607, defense response & 8 & $2.75 \times 10^{-3}$ & DDX58, NLRC5, IFIT1, TMEM173, PMAIP1, EIF2AK2, \\
to virus & & & CXCL10, DDIT4 \\
GO:0006977, DNA damage response, & 3 & $4.25 \times 10^{-3}$ & CDKN1A, MDM2, PIDD1 \\
signal transduction by p53 class & & & \\
mediator resulting in cell cycle arrest & & & \\
GO:0043029, T cell homeostasis & 4 & $4.90 \times 10^{-3}$ & RIPK3, PMAIP1, FAS, RC3H1 \\
GO:0000422, mitophagy & 4 & $6.37 \times 10^{-3}$ & ATG9B, GABARAPL1, ATG12, ATG2A \\
$\begin{array}{l}\text { GO:0070059, intrinsic apoptotic } \\
\text { signaling pathway in response to }\end{array}$ & 4 & $7.48 \times 10^{-3}$ & TNFRSF10B, BBC3, PMAIP1, APAF1 \\
endoplasmic reticulum stress & & & \\
\hline
\end{tabular}

GO, Gene Ontology.

Specific effect of cisplatin and Tet combination on HEI-OCI auditory cells. Of the 882 DEGs induced by the cisplatin and Tet combination, the 467 downregulated histone genes were involved in biological processes including 'nucleosome assembly' and 'nucleosome organization' (Table V), and one KEGG pathway of 'Systemic lupus erythematosus' (Table VI). The downregulated DEGs that were specifically induced by combination treatment, including cyclin-dependent kinase inhibitor 2A (CDKN2A) were related to biological processes like 'rRNA processing' and 'ncRNA metabolic process' (Table V). The downregulated CCND1 specifically responded to combination treatment was also involved in 'Focal adhesion' (Table VI).

The 415 upregulated genes (such as ZMAT3, PMAIP1, TRP53INP1, CDKN1A, BTG2, and FAS) were clustered in biological processes including 'programmed cell death', 'cell cycle', 'induction of apoptosis' and 'apoptosis' (Table V), as were the DEGs that were specifically upregulated by the combination treatment (including Caspase-3 (CASP3) and IL18 (Table V). Genes like CDKN1A, CASP3, ZMAT3, PMAIP1, and FAS were involved in 'p53 signaling pathway', and genes including CASP3, CDKN1A, and FAS were related to 'pathways in cancer', as were TCF7L1 and FZD6 genes that were specifically responded to combination treatment (Table VI).

Most of the 432 DEGs that were specifically induced by the combination treatment were associated with the biological processes and KEGG pathways that were similar to the functional categories associated with the 882 DEGs related to combination treatment (Table SII). For instance, downregulated genes including CDKN2A were related to the biological processes that related to the metabolism and biogenesis of ribosome and nucleosome, and the processing of RNAs (Table SII). upregulated CASP3 and IL18, were associated with 'positive regulation of apoptotic process' and 'positive regulation of cell death'. The 'Pathways in cancer' pathway enriched upregulated WNT9A, TCF7L1, and FZD6 (Table SII).

The expression patterns of several DEGs are shown in Fig. 5. The FPKM of ATG12, ATG2A, ZMAT3, DDIAS, TRP53INP1, TXNIP, CDKN1A, BTG2, PMAIP1, PIDD1 and Fas increased following treatment with cisplatin alone or in combination with Tet, compared with untreated control cells. By contrast, serpine1, THBS1 and IGFBP5 were downregulated.

The expression of IGF1 (Fig. 5B) decreased following cisplatin treatment but was rescued by the addition of Tet $(\mathrm{P}<0.05)$. FOXO3 expression followed the opposite pattern (Fig. 5C). In comparison with control and cisplatin alone, Tet treatment increased the expression of caspase 3, IGF2R, FZD6, IL18, TCF7L1, and decreased the expression of WNT2/4, CCND1 and CDKN2A (Fig. 5B and C). The gene expression changes induced specifically by Tet, and their associated biological processes, may serve an important role in inhibiting cisplatin-induced cytotoxicity in HEI-OC1 auditory cells.

Validation of protein expression. Protein expression of several DEGs was determined using western blot analysis. CDKN1A/p21 and Fas upregulation was cisplatin-dependent and Tet-independent (Fig. 5E). However, expression of CDKN2A/p16-INK4A and WNT2 were decreased, whereas TCF7L1, FZD6, and CASP3 were specifically upregulated by the combination of cisplatin and Tet.

\section{Discussion}

Cisplatin-associated ototoxicity is a major complication of cisplatin-based chemotherapy $(2,3,5)$. Cisplatin-induced 
Table II. Kyoto Encyclopedia of Genes and Genomes pathways associated with the differentially expressed genes induced by cisplatin vs. control.

\begin{tabular}{|c|c|c|c|}
\hline Term & Count & P-value & Gene name \\
\hline mmu05322, Systemic lupus erythematosus & 26 & $7.48 \times 10^{-19}$ & $\begin{array}{l}\text { HIST1H2AF, HIST1H2AG, HIST1H2BM, HIST1H4A, } \\
\text { HIST1H2BK, HIST1H4B, HIST1H2BL, HIST2H2AC, } \\
\text { HIST1H2BJ, HIST3H2A, etc. }\end{array}$ \\
\hline mmu05034, Alcoholism & 26 & $2.04 \times 10^{-15}$ & $\begin{array}{l}\text { HIST1H4A, HIST1H2BK, HIST1H4B, HIST1H2BL, } \\
\text { HIST2H2AC, HIST1H2BJ, HIST3H2A, H2AFX, } \\
\text { HIST1H4I, HIST1H4J, etc. }\end{array}$ \\
\hline mmu05203, Viral carcinogenesis & 15 & $2.98 \times 10^{-5}$ & $\begin{array}{l}\text { HIST1H2BB, HIST4H4, HIST1H2BH, HIST2H4, } \\
\text { HIST1H2BM, MRPS18B, HIST1H4A, HIST1H2BK, } \\
\text { HIST1H4B, HIST1H2BL, etc. }\end{array}$ \\
\hline mmu04510, Focal adhesion & 11 & $2.43 \times 10^{-3}$ & $\begin{array}{l}\text { PDGFB, TLN2, COL1A2, PDGFRB, IGF1, THBS1, } \\
\text { COL5A3, SPP1, PDGFC, COL3A1, SPP1, etc. }\end{array}$ \\
\hline $\begin{array}{l}\text { mmu05202, Transcriptional misregulation } \\
\text { in cancer }\end{array}$ & 9 & $6.42 \times 10^{-3}$ & $\begin{array}{l}\text { MAF, HIST2H3B, HIST1H3A, IGF1, PBX1, } \\
\text { HIST1H3G, ID2, H3F3B, HIST1H3F, }\end{array}$ \\
\hline mmu05206, MicroRNAs in cancer & 12 & $6.50 \times 10^{-3}$ & $\begin{array}{l}\text { PDGFB, PDGFRB, MARCKS, THBS1, IRS1, TPM1, } \\
\text { MIR17, MIR18, MIR20A, etc. }\end{array}$ \\
\hline mmu04151, PI3K-Akt signaling pathway & 13 & $1.45 \times 10^{-2}$ & $\begin{array}{l}\text { PDGFB, PDGFRB, IGF1, ANGPT1, THBS1, IRS1, } \\
\text { ANGPT4, SPP1, COL5A3, COL3A1, etc. }\end{array}$ \\
\hline mmu04512, ECM-receptor interaction & 6 & $1.59 \times 10^{-2}$ & $\begin{array}{l}\text { COL3A1, COL1A2, COL6A1, THBS1, COL5A3, } \\
\text { SPP1 }\end{array}$ \\
\hline mmu04015, Rap1 signaling pathway & 9 & $2.72 \times 10^{-2}$ & $\begin{array}{l}\text { PDGFB, TLN2, IGF1, ANGPT1, THBS1, ANGPT4, } \\
\text { MAGI1, PDGFRB, PDGFC }\end{array}$ \\
\hline mmu04066, HIF-1 signaling pathway & 6 & $2.81 \times 10^{-2}$ & EDN1, SERPINE1, HK2, IGF1, ANGPT1, ANGPT4 \\
\hline mmu04330, Notch signaling pathway & 4 & $4.86 \times 10^{-2}$ & DTX4, HES1, MAML3, LFNG \\
\hline
\end{tabular}

B, Upregulated genes

\begin{tabular}{|c|c|c|c|}
\hline Term & Count & P-value & Gene name \\
\hline mmu04115, p53 signaling pathway & 12 & $1.77 \times 10^{-10}$ & $\begin{array}{l}\text { CDKN1A, BBC3, ZMAT3, MDM2, PMAIP1, FAS, } \\
\text { CCNG1, PIDD1, SESN2, CCNG2, etc. }\end{array}$ \\
\hline mmu05169, Epstein-Barr virus infection & 8 & $8.93 \times 10^{-4}$ & $\begin{array}{l}\text { DDX58, CDKN1A, NFKBIE, RELB, NFKBIA, } \\
\text { MDM2, NFKB2, EIF2AK2 }\end{array}$ \\
\hline mmu05164, Influenza A & 8 & $3.32 \times 10^{-3}$ & $\begin{array}{l}\text { DDX58, TNFRSF10B, NFKBIA, H2-DMB1, FAS, } \\
\text { EIF2AK2, NXT2, CXCL10 }\end{array}$ \\
\hline mmu04068, FoxO signaling pathway & 7 & $4.21 \times 10^{-3}$ & $\begin{array}{l}\text { CDKN1A, GABARAPL1, ATG12, FBXO25, MDM2, } \\
\text { FOXO3, CCNG2 }\end{array}$ \\
\hline $\begin{array}{l}\text { mmu04623, Cytosolic DNA-sensing } \\
\text { pathway }\end{array}$ & 5 & $6.03 \times 10^{-3}$ & DDX58, TMEM173, RIPK3, NFKBIA, CXCL10 \\
\hline $\begin{array}{l}\text { mmu04622, RIG-I-like receptor signaling } \\
\text { pathway }\end{array}$ & 5 & $7.47 \times 10^{-3}$ & DDX58, TMEM173, ATG12, NFKBIA, CXCL10 \\
\hline mmu04142, Lysosome & 6 & $1.27 \times 10^{-2}$ & ABCB9, AP3M2, SMPD1, ARSA, SORT1, CTSF \\
\hline mmu05162, Measles & 6 & $1.95 \times 10^{-2}$ & $\begin{array}{l}\text { DDX58, TNFRSF10B, BBC3, NFKBIA, FAS, } \\
\text { EIF2AK2 }\end{array}$ \\
\hline mmu04064 NF-kappa B signaling pathway & 5 & $2.48 \times 10^{-2}$ & DDX58, RELB, NFKBIA, NFKB2, PIDD1 \\
\hline mmu04210, Apoptosis & 4 & $3.10 \times 10^{-2}$ & TNFRSF10B, NFKBIA, FAS, APAF1 \\
\hline mmu05206, MicroRNAs in cancer & 8 & $3.82 \times 10^{-2}$ & $\begin{array}{l}\text { NOTCH3, CDKN1A, RASSF1, MDM2, CCNG1, } \\
\text { DDIT4, PDCD4, MIR34A }\end{array}$ \\
\hline mmu05203, Viral carcinogenesis & 7 & $4.85 \times 10^{-2}$ & $\begin{array}{l}\text { CDKN1A, KAT2B, NFKBIA, MDM2, PMAIP1, } \\
\text { NFKB2, EIF2AK2 }\end{array}$ \\
\hline
\end{tabular}


Table III. The top 20 biological processes associated with the differentially expressed genes overlapping between cisplatin vs. control and combination vs. control groups.

A, Downregulated genes

\begin{tabular}{|c|c|c|c|}
\hline Term & Count & P-value & Gene name \\
\hline GO:0006334, nucleosome assembly & 18 & $4.24 \times 10^{-18}$ & $\begin{array}{l}\text { H1F0, HIST1H2BB, HIST4H4, HIST1H1C, HIST1H2AF, } \\
\text { HIST1H1B, HIST1H2AG, HIST1H1A, HIST1H2BH, } \\
\text { HIST2H4, etc. }\end{array}$ \\
\hline GO:0031497, chromatin assembly & 18 & $6.98 \times 10^{-18}$ & $\begin{array}{l}\text { H1F0, HIST1H2BB, HIST4H4, HIST1H1C, HIST1H2AF, } \\
\text { HIST1H1B, HIST1H2AG, HIST1H1A, HIST1H2BH, } \\
\text { HIST2H4, etc. }\end{array}$ \\
\hline GO:0034728, nucleosome organization & 18 & $8.89 \times 10^{-18}$ & $\begin{array}{l}\text { H1F0, HIST1H2BB, HIST4H4, HIST1H1C, HIST1H2AF, } \\
\text { HIST1H1B, HIST1H2AG, HIST1H1A, HIST1H2BH, } \\
\text { HIST2H4, etc. }\end{array}$ \\
\hline $\begin{array}{l}\text { GO:0065004, protein-DNA complex } \\
\text { assembly }\end{array}$ & 18 & $8.89 \times 10^{-18}$ & $\begin{array}{l}\text { H1F0, HIST1H2BB, HIST4H4, HIST1H1C, HIST1H2AF, } \\
\text { HIST1H1B, HIST1H2AG, HIST1H1A, HIST1H2BH, } \\
\text { HIST2H4, etc. }\end{array}$ \\
\hline GO:0006323, DNA packaging & 18 & $1.55 \times 10^{-15}$ & $\begin{array}{l}\text { H1F0, HIST1H2BB, HIST4H4, HIST1H1C, HIST1H2AF, } \\
\text { HIST1H1B, HIST1H2AG, HIST1H1A, HIST1H2BH, } \\
\text { HIST2H4, etc. }\end{array}$ \\
\hline $\begin{array}{l}\text { GO:0006333, chromatin assembly } \\
\text { or disassembly }\end{array}$ & 18 & $5.73 \times 10^{-15}$ & $\begin{array}{l}\text { H1F0, HIST1H2BB, HIST4H4, HIST1H1C, HIST1H2AF, } \\
\text { HIST1H1B, HIST1H2AG, HIST1H1A, HIST1H2BH, } \\
\text { HIST2H4, etc. }\end{array}$ \\
\hline $\begin{array}{l}\text { GO:0034622, cellular macromolecular } \\
\text { complex assembly }\end{array}$ & 19 & $5.45 \times 10^{-11}$ & $\begin{array}{l}\text { H1F0, HIST1H2BB, HIST4H4, HIST1H1C, HIST1H2AF, } \\
\text { HIST1H1B, HIST1H2AG, HIST1H1A, HIST1H2BH, } \\
\text { CTTNBP2, etc. }\end{array}$ \\
\hline $\begin{array}{l}\text { GO:0034621, cellular macromolecular } \\
\text { complex subunit organization }\end{array}$ & 19 & $4.01 \times 10^{-10}$ & $\begin{array}{l}\text { H1F0, HIST1H2BB, HIST4H4, HIST1H1C, HIST1H2AF, } \\
\text { HIST1H1B, HIST1H2AG, HIST1H1A, HIST1H2BH, } \\
\text { CTTNBP2, etc. }\end{array}$ \\
\hline $\begin{array}{l}\text { GO:0065003, macromolecular complex } \\
\text { assembly }\end{array}$ & 19 & $6.33 \times 10^{-8}$ & $\begin{array}{l}\text { H1F0, HIST1H2BB, HIST4H4, HIST1H1C, HIST1H2AF, } \\
\text { HIST1H1B, HIST1H2AG, HIST1H1A, HIST1H2BH, } \\
\text { CTTNBP2, etc. }\end{array}$ \\
\hline GO:0006325, chromatin organization & 18 & $1.25 \times 10^{-7}$ & $\begin{array}{l}\text { H1F0, HIST1H2BB, HIST4H4, HIST1H1C, HIST1H2AF, } \\
\text { HIST1H1B, HIST1H2AG, HIST1H1A, HIST1H2BH, } \\
\text { HIST2H4, etc. }\end{array}$ \\
\hline $\begin{array}{l}\text { GO:0043933, macromolecular complex } \\
\text { subunit organization }\end{array}$ & 19 & $2.18 \times 10^{-7}$ & $\begin{array}{l}\text { H1F0, HIST1H2BB, HIST4H4, HIST1H1C, HIST1H2AF, } \\
\text { HIST1H1B, HIST1H2AG, HIST1H1A, HIST1H2BH, } \\
\text { CTTNBP2, etc. }\end{array}$ \\
\hline GO:0051276, chromosome organization & 18 & $3.94 \times 10^{-6}$ & $\begin{array}{l}\text { H1F0, HIST1H2BB, HIST4H4, HIST1H1C, HIST1H2AF, } \\
\text { HIST1H1B, HIST1H2AG, HIST1H1A, HIST1H2BH, } \\
\text { HIST2H4, etc. }\end{array}$ \\
\hline $\begin{array}{l}\text { GO:0030855, epithelial cell } \\
\text { differentiation }\end{array}$ & 8 & $5.36 \times 10^{-4}$ & $\begin{array}{l}\text { SPRR1A, SPRR1B, GJA1, SPRR2G, PTCH1, ID3, FZD2, } \\
\text { SPRR2K }\end{array}$ \\
\hline GO:0007507, heart development & 10 & $1.09 \times 10^{-3}$ & $\begin{array}{l}\text { NRP2, ID2, EDN1, GJA1, FHL2, PTCH1, ADAMTS1, ID3, } \\
\text { MECOM, TPM1 }\end{array}$ \\
\hline GO:0031424, keratinization & 4 & $3.94 \times 10^{-3}$ & SPRR1A, SPRR1B, SPRR2G, SPRR2K \\
\hline GO:0060429, epithelium development & 10 & $4.08 \times 10^{-3}$ & $\begin{array}{l}\text { SPRR1A, LMO4, SPRR1B, GJA1, SPRR2G, PTCH1, ID3, } \\
\text { FZD2, MECOM, SPRR2K }\end{array}$ \\
\hline $\begin{array}{l}\text { GO: } 0042325 \text {, regulation of } \\
\text { phosphorylation }\end{array}$ & 10 & $6.31 \times 10^{-3}$ & $\begin{array}{l}\text { SPRY1, PDGFB, SOCS3, EDN1, PDGFRB, TRIB3, CD24A, } \\
\text { PPP1R14B, IRS1, TRIB1 }\end{array}$ \\
\hline $\begin{array}{l}\text { GO:0019220, regulation of phosphate } \\
\text { metabolic process }\end{array}$ & 10 & $7.97 \times 10^{-3}$ & $\begin{array}{l}\text { SPRY1, PDGFB, SOCS3, EDN1, PDGFRB, TRIB3, CD24A, } \\
\text { PPP1R14B, IRS1, TRIB1 }\end{array}$ \\
\hline $\begin{array}{l}\text { GO: } 0051174 \text {, regulation of phosphorus } \\
\text { metabolic process }\end{array}$ & 10 & $7.97 \times 10^{-3}$ & $\begin{array}{l}\text { SPRY1, PDGFB, SOCS3, EDN1, PDGFRB, TRIB3, CD24A, } \\
\text { PPP1R14B, IRS1, TRIB1 }\end{array}$ \\
\hline $\begin{array}{l}\text { GO:0043009, chordate embryonic } \\
\text { development }\end{array}$ & 12 & $9.30 \times 10^{-3}$ & $\begin{array}{l}\text { HES1, SFRP2, EDN1, NLE1, PDGFRB, GJA1, PTCH1, } \\
\text { GAS1, MECOM, TPM1, etc. }\end{array}$ \\
\hline
\end{tabular}


Table III. Continued.

B, Upregulated genes

\begin{tabular}{|c|c|c|c|}
\hline Term & Count & P-value & Gene name \\
\hline GO:0012501, programmed cell death & 16 & $1.95 \times 10^{-5}$ & $\begin{array}{l}\text { TRP53INP1, FAS, DDIT4, CKAP2, ZMAT3, EDA2R, } \\
\text { PMAIP1, PDCD4, TMEM173, NOD1, etc. }\end{array}$ \\
\hline GO:0008219, cell death & 16 & $4.35 \times 10^{-5}$ & $\begin{array}{l}\text { TRP53INP1, FAS, DDIT4, CKAP2, ZMAT3, EDA2R, } \\
\text { PMAIP1, PDCD4, TMEM173, NOD1, etc. }\end{array}$ \\
\hline GO:0016265, death & 16 & $5.68 \times 10^{-5}$ & $\begin{array}{l}\text { TRP53INP1, FAS, DDIT4, CKAP2, ZMAT3, EDA2R, } \\
\text { PMAIP1, PDCD4, TMEM173, NOD1, etc. }\end{array}$ \\
\hline GO:0006915, apoptosis & 15 & $6.61 \times 10^{-5}$ & $\begin{array}{l}\text { TRP53INP1, APAF1, FAS, CKAP2, ZMAT3, PMAIP1, } \\
\text { PDCD4, DDIT4, TMEM173, NOD1, etc. }\end{array}$ \\
\hline GO:0007049, cell cycle & 16 & $3.41 \times 10^{-4}$ & $\begin{array}{l}\text { CKAP2, TXNIP, KAT2B, CCNG1, SESN2, CDKN1A, } \\
\text { EREG, RASSF1, TRP53INP1, MDM2, etc. }\end{array}$ \\
\hline GO:0007050, cell cycle arrest & 5 & $1.64 \times 10^{-3}$ & CDKN1A, AK1, RASSF1, TRP53INP1, SESN2 \\
\hline GO:0022402, cell cycle process & 11 & $2.67 \times 10^{-3}$ & $\begin{array}{l}\text { CDKN1A, EREG, AK1, RASSF1, TRP53INP1, MDM2, } \\
\text { SESN2, CCNG1, CCNG2, SMC4, etc. }\end{array}$ \\
\hline GO:0033554, cellular response to stress & 11 & $3.25 \times 10^{-3}$ & $\begin{array}{l}\text { POLK, CLSPN, CDKN1A, ERCC5, ATG9B, ATG12, BTG2, } \\
\text { ZMAT3, PMAIP1, EIF2AK2, etc. }\end{array}$ \\
\hline $\begin{array}{l}\text { GO:0012502, induction of programmed } \\
\text { cell death }\end{array}$ & 7 & $3.78 \times 10^{-3}$ & $\begin{array}{l}\text { NOD1, RIPK3, TRP53INP1, PMAIP1, FAS, APAF1, } \\
\text { PHLDA3 }\end{array}$ \\
\hline GO:0006917, induction of apoptosis & 7 & $3.78 \times 10^{-3}$ & $\begin{array}{l}\text { NOD1, RIPK3, TRP53INP1, PMAIP1, FAS, APAF1, } \\
\text { PHLDA3 }\end{array}$ \\
\hline $\begin{array}{l}\text { GO:0043068, positive regulation of } \\
\text { programmed cell death }\end{array}$ & 8 & $7.02 \times 10^{-3}$ & $\begin{array}{l}\text { CDKN1A, NOD1, RIPK3, TRP53INP1, PMAIP1, FAS, } \\
\text { APAF1, PHLDA3 }\end{array}$ \\
\hline $\begin{array}{l}\text { GO:0010942, positive regulation of } \\
\text { cell death }\end{array}$ & 8 & $7.32 \times 10^{-3}$ & $\begin{array}{l}\text { CDKN1 A, NOD1, RIPK3, TRP53INP1, PMAIP1, FAS, } \\
\text { APAF1, PHLDA3 }\end{array}$ \\
\hline $\begin{array}{l}\text { GO:0006974, response to DNA damage } \\
\text { stimulus }\end{array}$ & 8 & $1.43 \times 10^{-2}$ & $\begin{array}{l}\text { POLK, CLSPN, CDKN1A, ERCC5, BTG2, ZMAT3, } \\
\text { PMAIP1, PHLDA3 }\end{array}$ \\
\hline $\begin{array}{l}\text { GO:0045596, negative regulation of cell } \\
\text { differentiation }\end{array}$ & 6 & $2.33 \times 10^{-2}$ & NOTCH3, EREG, GDF11, NFKBIA, RC3H1, TOB1 \\
\hline $\begin{array}{l}\text { GO:0043065, positive regulation of } \\
\text { apoptosis }\end{array}$ & 7 & $2.35 \mathrm{x}^{1} 0^{-2}$ & $\begin{array}{l}\text { NOD1, RIPK3, TRP53INP1, PMAIP1, FAS, APAF1, } \\
\text { PHLDA3 }\end{array}$ \\
\hline GO:0008104, protein localization & 13 & $3.59 \times 10^{-2}$ & $\begin{array}{l}\text { ARL6IP1, TXNIP, GDI1, ABCB9, CHMP5, ZMAT3, } \\
\text { NFKBIA, PMAIP1, OPTN, CXCL10, etc. }\end{array}$ \\
\hline GO:0007033, vacuole organization & 3 & $3.67 \times 10^{-2}$ & ATG9B, ATG12, CHMP5 \\
\hline GO:0009411, response to UV & 3 & $3.87 \times 10^{-2}$ & CDKN1A, ERCC5, PMAIP1 \\
\hline
\end{tabular}

GO, Gene Ontology.

cytotoxicity, DNA damage and apoptosis in cochlear hair cells contribute to cisplatin-associated ototoxicity $(10,12-14)$. The present study demonstrated that cisplatin-induced ototoxicity in HEI-OC1 auditory cells was associated with the inhibition of cell viability and dysregulation of genes related to apoptosis, cell cycle arrest and several pathways, including the p53, HIF-1, Wnt and PI3K-Akt signaling pathways. Treatment with Tet protected HEI-OC1 auditory cells against cisplatin-induced cytotoxicity in vitro and regulated several signaling pathways.

The synergistic effect of Tan IIA on cisplatin-induced cytotoxicity in cancer cells has been previously reported (18). Indeed, Tan IIA was previously observed to enhance cisplatin-induced apoptosis and cell cycle arrest at the $S$ phase in human prostate cancer cells (18). In another study, Tan IIA promoted apoptosis and cell cycle arrest at the sub- $\mathrm{G}_{1}$ phase in human hepatocellular carcinoma cells (19). Du et al (16) demonstrated that 24-h Tan IIA treatments at concentrations $<64 \mathrm{mg} / \mathrm{l}$ could alleviate radiation-induced cytotoxicity and apoptosis of HEI-OC1 auditory cells by inhibiting p65/nuclear factor $\kappa \mathrm{B}$ p53 and p21 signaling pathways. Du et al (16) also indicated that Tan IIA at concentrations $>16 \mathrm{mg} / 1$ resulted in significant cytotoxicity, whereas Tan IIA $<8 \mathrm{mg} / 1$ had no cytotoxic effects on HEI-OC1 cells. However, the present study determined that Tan IIA concentrations as low as $1.5 \mathrm{mg} / \mathrm{l}$ augmented the effect of cisplatin on cell viability of HEI-OC1 auditory cells. This difference might be due to the longer treatment period in the present study, compared with Du et al (16) (30 and $24 \mathrm{~h}$, respectively). Thus, it may be hypothesized that 
Table IV. Kyoto Encyclopedia of Genes and Genomes (KEGG) pathways associated with the differentially expressed genes overlapping between cisplatin vs. control and combination vs. control groups.

A, Downregulated genes

\begin{tabular}{|c|c|c|c|}
\hline Term & Count & P-value & Gene name \\
\hline mmu05322, Systemic lupus erythematosus & 14 & $3.29 \times 10^{-10}$ & $\begin{array}{l}\text { HIST1H2BB, HIST4H4, HIST1H2AF, HIST1H2AG, } \\
\text { HIST1H2BH, HIST2H4, HIST1H2BM, HIST1H4A, } \\
\text { H3F3B, H2AFX, etc. }\end{array}$ \\
\hline mmu04510, Focal adhesion & 9 & $3.42 \times 10^{-3}$ & $\begin{array}{l}\text { GM12715, PDGFB, COL3A1, COL1A2, PDGFRB, } \\
\text { COL6A1, THBS1, COL5A3, SPP1 }\end{array}$ \\
\hline mmu04512, ECM-receptor interaction & 6 & $3.90 \times 10^{-3}$ & $\begin{array}{l}\text { COL3A1, COL1A2, COL6A1, THBS1, COL5A3, } \\
\text { SPP1 }\end{array}$ \\
\hline mmu04330, Notch signaling pathway & 4 & $2.53 \times 10^{-2}$ & DTX4, HES1, MAML3, LFNG \\
\hline
\end{tabular}

B, Upregulated genes

\begin{tabular}{|c|c|c|c|}
\hline Term & Count & P-value & Gene name \\
\hline mmu04115, p53 signaling pathway & 10 & $6.27 \times 10^{-9}$ & $\begin{array}{l}\text { CDKN1 A, ZMAT3, MDM2, PMAIP1, FAS, APAF1, } \\
\text { SESN2, CCNG1, CCNG2, GTSE1 }\end{array}$ \\
\hline mmu04623, Cytosolic DNA-sensing pathway & 5 & $1.35 \times 10^{-3}$ & DDX58, TMEM173, RIPK3, NFKBIA, CXCL10 \\
\hline mmu04622, RIG-I-like receptor signaling pathway & 5 & $2.97 \times 10^{-3}$ & DDX58, TMEM173, ATG12, NFKBIA, CXCL10 \\
\hline mmu04210, Apoptosis & 4 & $4.16 \times 10^{-2}$ & TNFRSF10B, NFKBIA, FAS, APAF1 \\
\hline
\end{tabular}

A

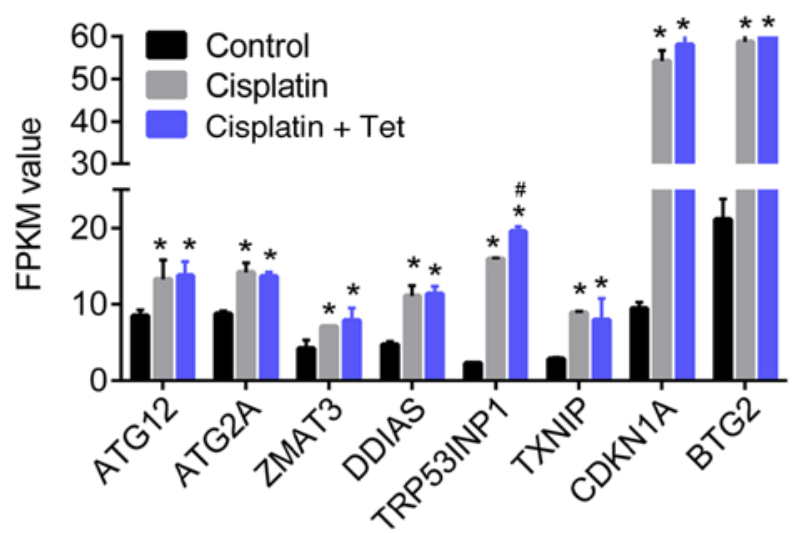

C

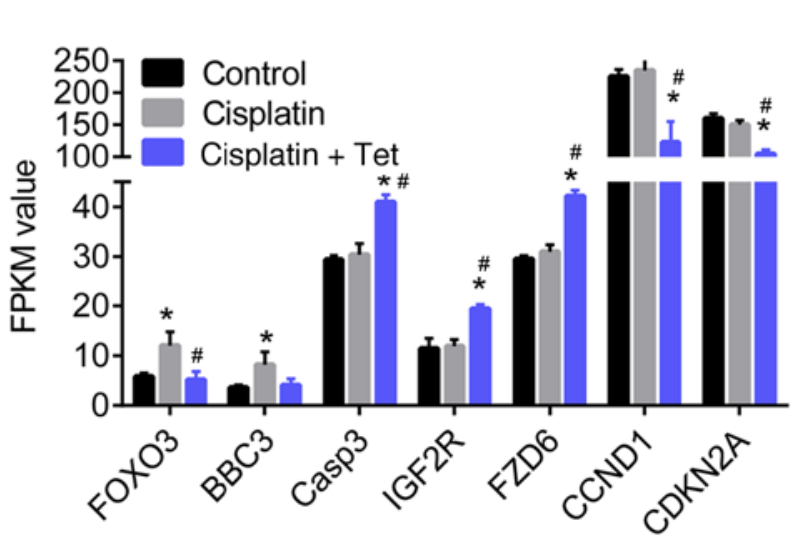

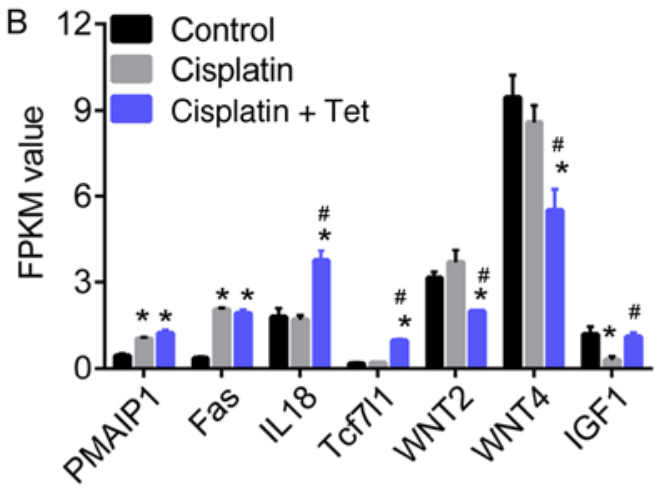

D

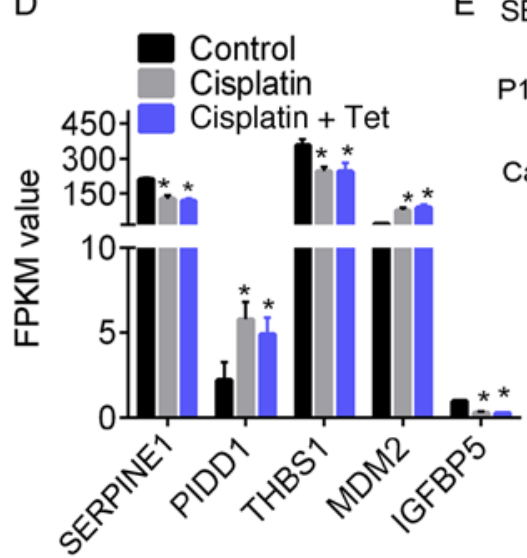

Figure 5. FPKM values and expression of several DEGs in the three groups. (A-D) FPKM values of several random selected up- or downregulated DEGs with typical expression profiling in response to treatment with cisplatin alone or combined with Tet. (E) Expression of several protein products of DEGs. ${ }^{*}<0.05$, vs. control. ${ }^{~} \mathrm{P}<0.05$ vs. Cisplatin. The differences were analyzed by one-way ANOVA followed by Tukey's post hoc test. DEG, differentially expressed gene; FKPM, fragments per kilobase of exon model per million reads mapped. 
Table V. The top 20 biological processes associated with the differentially expressed genes induced by combination treatment compared with control.

Downregulated genes

\begin{tabular}{|c|c|c|c|}
\hline Term & Count & P-value & Gene name \\
\hline GO:0006334, nucleosome assembly & 19 & $3.03 \times 10^{-14}$ & $\begin{array}{l}\text { HIST1H2AB, HIST4H4, HIST1H4K, HIST1H2AF, } \\
\text { HIST1H2AG, HIST1H2BM, HIST1H2BK, HIST1H4A, } \\
\text { HIST1H4B, HIST2H2AC, etc. }\end{array}$ \\
\hline GO:0031497, chromatin assembly & 19 & $5.06 \times 10^{-14}$ & $\begin{array}{l}\text { HIST1H2AB, HIST4H4, HIST1H4K, HIST1H2AF, } \\
\text { HIST1H2AG, HIST1H2BM, HIST1H2BK, HIST1H4A, } \\
\text { HIST1H4B, HIST2H2AC, etc. }\end{array}$ \\
\hline GO:0065004, protein-DNA complex & 19 & $6.50 \times 10^{-14}$ & HIST1H2AB, HIST4H4, HIST1H4K, HIST1H2AF, \\
\hline assembly & & & $\begin{array}{l}\text { HIST1H2AG, HIST1H2BM, HIST1H2BK, HIST1H4A, } \\
\text { HIST1H4B, HIST2H2AC, etc. }\end{array}$ \\
\hline $\begin{array}{l}\text { GO:0034728, nucleosome } \\
\text { organization }\end{array}$ & 19 & $6.50 \times 10^{-14}$ & $\begin{array}{l}\text { HIST1H2AB, HIST4H4, HIST1H4K, HIST1H2AF, } \\
\text { HIST1H2AG, HIST1H2BM, HIST1H2BK, HIST1H4A, } \\
\text { HIST1H4B, HIST2H2AC, etc. }\end{array}$ \\
\hline $\begin{array}{l}\text { GO:0034622, cellular macromo } \\
\text { lecular complex assembly }\end{array}$ & 28 & $6.42 \times 10^{-13}$ & $\begin{array}{l}\text { EIF6, FKBP4, WNT2, HIST1H2BM, HIST1H4A, PRMT5, } \\
\text { TUBA1C, NIP7, HIST1H1A, HIST1H2BH, FLNA, etc. }\end{array}$ \\
\hline GO:0042254, ribosome biogenesis & 20 & $7.62 \times 10^{-12}$ & $\begin{array}{l}\text { EIF6, NAF1, EXOSC4, NIP7, BOP1, IMP3, CDKN2A, } \\
\text { NPM1, RRS1, NHP2, etc. }\end{array}$ \\
\hline GO:0034470, ncRNA processing & 23 & $9.92 \times 10^{-12}$ & $\begin{array}{l}\text { NAF1, BOP1, RRP9, QTRT1, EXOSC1, TRMT61A, FBL, } \\
\text { IMP3, NOP2, CDKN2A, etc. }\end{array}$ \\
\hline GO:0006323, DNA packaging & 19 & $1.16 \times 10^{-11}$ & $\begin{array}{l}\text { HIST1H2AB, HIST4H4, HIST1H4K, HIST1H2AF, } \\
\text { HIST1H2AG, HIST1H2BM, HIST1H2BK, HIST1H4A, } \\
\text { HIST1H4B, HIST2H2AC, etc. }\end{array}$ \\
\hline $\begin{array}{l}\text { GO:0034621, cellular macromolecular } \\
\text { complex subunit organization }\end{array}$ & 28 & $1.17 \times 10^{-11}$ & $\begin{array}{l}\text { HIST1H2AB, EIF6, FKBP4, WNT2, CTTNBP2, NIP7, } \\
\text { FLNA, HIST2H4, HIST1H3A, CACNA1A, etc. }\end{array}$ \\
\hline $\begin{array}{l}\text { GO:0022613, ribonucleoprotein } \\
\text { complex biogenesis }\end{array}$ & 21 & $3.69 \times 10^{-11}$ & $\begin{array}{l}\text { EIF6, NAF1, RRP9, FBL, IMP3, NOP2, CDKN2A, PRMT5, } \\
\text { NPM1, RRS1, etc. }\end{array}$ \\
\hline $\begin{array}{l}\text { GO:0006333, chromatin assembly or } \\
\text { disassembly }\end{array}$ & 19 & $4.39 \times 10^{-11}$ & $\begin{array}{l}\text { HIST1H2AB, HIST4H4, HIST1H4K, HIST1H2AF, } \\
\text { HIST1H2AG, HIST1H2BM, HIST1H2BK, HIST1H4A, } \\
\text { HIST1H4B, HIST2H2AC, etc. }\end{array}$ \\
\hline $\begin{array}{l}\text { GO:0034660, ncRNA metabolic } \\
\text { process }\end{array}$ & 24 & $2.17 \times 10^{-10}$ & $\begin{array}{l}\text { NAF1, PUS1, EXOSC4, BOP1, QTRT1, EXOSC1, } \\
\text { TRMT61A, IMP3, CDKN2A, METTL1, etc. }\end{array}$ \\
\hline $\begin{array}{l}\text { GO:0065003, macromolecular } \\
\text { complex assembly }\end{array}$ & 30 & $8.60 \times 10^{-10}$ & $\begin{array}{l}\text { HIST4H4, FKBP4, WNT2, CTTNBP2, PRMT5, NPM1, } \\
\text { MYC, TUBA1C, NIP7, FLNA, etc. }\end{array}$ \\
\hline $\begin{array}{l}\text { GO:0043933, macromolecular } \\
\text { complex subunit organization }\end{array}$ & 30 & $5.71 \times 10^{-9}$ & $\begin{array}{l}\text { HIST1H2AB, EIF6, FKBP4, WNT2, CTTNBP2, PRMT5, } \\
\text { NPM1, MYC, NIP7, etc. }\end{array}$ \\
\hline GO:0006364, rRNA processing & 13 & $9.96 \times 10^{-8}$ & $\begin{array}{l}\text { NAF1, EXOSC4, EXOSC1, BOP1, FBL, RCL1, IMP3, } \\
\text { NOP2, CDKN2A, NHP2, etc. }\end{array}$ \\
\hline GO:0016072, rRNA metabolic process & 13 & $1.16 \times 10^{-7}$ & $\begin{array}{l}\text { NAF1, EXOSC4, EXOSC1, BOP1, FBL, RCL1, IMP3, } \\
\text { NOP2, CDKN2A, NHP2, etc. }\end{array}$ \\
\hline GO:0006396, RNA processing & 29 & $8.47 \times 10^{-7}$ & $\begin{array}{l}\text { NAF1, BOP1, QTRT1, IMP3, CDKN2A, METTL1, PRMT5, } \\
\text { TSEN2, EXOSC4, RPP40, etc. }\end{array}$ \\
\hline GO:0008033, tRNA processing & 11 & $3.90 \times 10^{-6}$ & $\begin{array}{l}\text { PUS7L, ELAC2, PUS1, METTL1, WDR4, QTRT1, TSEN2, } \\
\text { TRMT61A, NSUN2, FBL, etc. }\end{array}$ \\
\hline GO:0006399, tRNA metabolic process & 12 & $5.36 \times 10^{-5}$ & $\begin{array}{l}\text { PUS7L, ELAC2, PUS1, METTL1, WDR4, QTRT1, TSEN2, } \\
\text { TRMT61A, RPP40, FBL, etc. }\end{array}$ \\
\hline GO:0006325, chromatin organization & 20 & $1.14 \times 10^{-4}$ & $\begin{array}{l}\text { HIST1H2AB, PRMT5, H2AFZ, H1F0, HIST1H2BB, } \\
\text { HIST1H1C, HIST1H1B, HIST1H1A, HIST1H2BH, } \\
\text { HIST2H4, etc. }\end{array}$ \\
\hline
\end{tabular}


Table V. Continued.

Upregulated genes

\begin{tabular}{|c|c|c|c|}
\hline Term & Count & P-value & Gene name \\
\hline GO:0012501, programmed cell death & 21 & $1.23 \times 10^{-5}$ & $\begin{array}{l}\text { CKAP2, ZMAT3, PMAIP1, BCL2L11, DDIT4, TMEM173, } \\
\text { CASP3, TRP53INP1, FAS, PHLDA3, etc. }\end{array}$ \\
\hline GO:0007049, cell cycle & 24 & $1.75 \times 10^{-5}$ & $\begin{array}{l}\text { TXNIP, CKAP2, NUSAP1, CCNG1, NCAPD3, BRCA1, } \\
\text { CDKN1A, RASSF1, TRP53INP1, MDM2, etc. }\end{array}$ \\
\hline $\begin{array}{l}\text { GO: } 0012502 \text {, induction of } \\
\text { programmed cell death }\end{array}$ & 12 & $2.50 \times 10^{-5}$ & $\begin{array}{l}\text { SERINC3, CASP3, CASP4, NOD1, IL18, RIPK3, } \\
\text { TRP53INP1, PMAIP1, FAS, APAF1, etc. }\end{array}$ \\
\hline GO:0006917, induction of apoptosis & 12 & $2.50 \times 10^{-5}$ & $\begin{array}{l}\text { SERINC3, CASP3, CASP4, NOD1, IL18, RIPK3, } \\
\text { TRP53INP1, PMAIP1, FAS, APAF1, etc. }\end{array}$ \\
\hline GO:0006915, apoptosis & 20 & $3.28 \times 10^{-5}$ & $\begin{array}{l}\text { CKAP2, ZMAT3, PMAIP1, PDCD4, DDIT4, CASP3, } \\
\text { TMEM173, TRP53INP1, JAK2, FAS, etc. }\end{array}$ \\
\hline GO:0008219, cell death & 21 & $3.32 \times 10^{-5}$ & $\begin{array}{l}\text { JAK2, FAS, CKAP2, ZMAT3, EDA2R, PMAIP1, DDIT4, } \\
\text { TMEM173, CASP3, TRP53INP1, etc. }\end{array}$ \\
\hline GO:0022402, cell cycle process & 18 & $4.28 \times 10^{-5}$ & $\begin{array}{l}\text { NUSAP1, CCNG1, SESN2, CCNG2, NCAPD3, BRCA1, } \\
\text { CDKN1A, RASSF1, TRP53INP1, MDM2, etc. }\end{array}$ \\
\hline GO:0016265, death & 21 & $4.61 \times 10^{-5}$ & $\begin{array}{l}\text { TRP53INP1, JAK2, FAS, CKAP2, ZMAT3, PMAIP1, } \\
\text { PDCD4, TAX1BP1, BCL2L11, DDIT4, etc. }\end{array}$ \\
\hline $\begin{array}{l}\text { GO: } 0043068 \text {, positive regulation of } \\
\text { programmed cell death }\end{array}$ & 14 & $5.61 \times 10^{-5}$ & $\begin{array}{l}\text { PMAIP1, BCL2L11, BRCA1, SERINC3, CDKN1A, CASP3, } \\
\text { CASP4, NOD1, TRP53INP1, FAS, etc. }\end{array}$ \\
\hline $\begin{array}{l}\text { GO: } 0010942 \text {, positive regulation of } \\
\text { cell death }\end{array}$ & 14 & $6.06 \times 10^{-5}$ & $\begin{array}{l}\text { PMAIP1, BCL2L11, BRCA1, SERINC3, CDKN1A, CASP3, } \\
\text { CASP4, NOD1, TRP53INP1, FAS, etc. }\end{array}$ \\
\hline $\begin{array}{l}\text { GO: } 0043065 \text {, positive regulation of } \\
\text { apoptosis }\end{array}$ & 13 & $2.13 \times 10^{-4}$ & $\begin{array}{l}\text { PMAIP1, BCL2L11, BRCA1, SERINC3, CASP3, RIPK3, } \\
\text { TRP53INP1, APAF1, FAS, PHLDA3, etc. }\end{array}$ \\
\hline GO:0007050, cell cycle arrest & 6 & $1.23 \times 10^{-3}$ & GAS2L3, CDKN1A, AK1, RASSF1, TRP53INP1, SESN2 \\
\hline GO:0042981, regulation of apoptosis & 18 & $2.19 \times 10^{-3}$ & $\begin{array}{l}\text { IL18, PMAIP1, TAX1BP1, BRCA1, SERINC3, CASP3, } \\
\text { CDKN1A, BTG2, TRP53INP1, FAS, etc. }\end{array}$ \\
\hline $\begin{array}{l}\text { GO: } 0043067 \text {, regulation of } \\
\text { programmed cell death }\end{array}$ & 18 & $2.49 \times 10^{-3}$ & $\begin{array}{l}\text { IL18, PMAIP1, TAX1BP1, BRCA1, SERINC3, CASP3, } \\
\text { CDKN1A, BTG2, TRP53INP1, FAS, etc. }\end{array}$ \\
\hline GO:0010941, regulation of cell death & 18 & $2.63 \times 10^{-3}$ & $\begin{array}{l}\text { IL18, PMAIP1, TAX1BP1, BRCA1, SERINC3, CASP3, } \\
\text { CDKN1A, BTG2, TRP53INP1, FAS, etc. }\end{array}$ \\
\hline $\begin{array}{l}\text { GO: } 0007076 \text {, mitotic chromosome } \\
\text { condensation }\end{array}$ & 3 & $3.98 \times 10^{-3}$ & NUSAP1, NCAPD3, SMC4 \\
\hline $\begin{array}{l}\text { GO:0033554, cellular response to } \\
\text { stress }\end{array}$ & 14 & $4.91 \times 10^{-3}$ & $\begin{array}{l}\text { POLK, ATG9B, ATG12, NEIL3, ZMAT3, PMAIP1, BRCA1, } \\
\text { CASP3, CDKN1A, BTG2, etc. }\end{array}$ \\
\hline GO:0007067, mitosis & 9 & $5.62 \times 10^{-3}$ & $\begin{array}{l}\text { SPC25, KNTC1, NUSAP1, NDC80, CEP55, CCNG1, } \\
\text { CCNG2, NCAPD3, SMC4 }\end{array}$ \\
\hline GO:0000280, nuclear division & 9 & $5.62 \times 10^{-3}$ & $\begin{array}{l}\text { SPC25, KNTC1, NUSAP1, NDC80, CEP55, CCNG1, } \\
\text { CCNG2, NCAPD3, SMC4 }\end{array}$ \\
\hline $\begin{array}{l}\text { GO: } 0000087, \mathrm{M} \text { phase of mitotic } \\
\text { cell cycle }\end{array}$ & 9 & $6.38 \times 10^{-3}$ & $\begin{array}{l}\text { SPC25, KNTC1, NUSAP1, NDC80, CEP55, CCNG1, } \\
\text { CCNG2, NCAPD3, SMC4 }\end{array}$ \\
\hline
\end{tabular}

GO, Gene Ontology.

Tan IIA-induced cytotoxicity to HEI-OC1 auditory cells is time-dependent, since the concentration used in the present study was far below the $\mathrm{IC}_{50}$ value of $151.8 \mathrm{mg} / \mathrm{l}$.

By contrast, low concentrations of Tet $(37.5$ and $70 \mathrm{mg} / \mathrm{l})$ exerted a protective effect against cisplatin-induced cytotoxicity. RNA-seq analysis was carried out to examine the underlying molecular mechanism. Cisplatin inhibited the viability of HEI-OC1 auditory cells by decreasing the expression of Hist1 and Hist2 gene clusters that are associated with DNA replication and actively transcribed in differentiating cells (20). Cisplatin also inhibited the expression of genes related to cell migration and proliferation, including IGF1 and IGFBP5. The expression of IGF1, IGF receptors and IGFBPs has been reported to induce or promote the 
Table VI. Kyoto Encyclopedia of Genes and Genomes pathways associated with the differentially expressed genes induced by combination treatment compared with control.

A, Downregulated genes

\begin{tabular}{|c|c|c|c|}
\hline Term & Count & P-value & Gene name \\
\hline mmu05322, Systemic lupus erythematosus & 15 & $1.94 \times 10^{-7}$ & $\begin{array}{l}\text { HIST1H2AB, HIST4H4, HIST1H4K, HIST1H2AF, } \\
\text { HIST1H2AG, HIST1H2BM, HIST1H2BK, HIST1H4A, } \\
\text { HIST1H4B, HIST2H2AC, etc. }\end{array}$ \\
\hline mmu03010, Ribosome & 10 & $3.36 \times 10^{-4}$ & $\begin{array}{l}\text { RPS19, RPL41, RPLP1, GM10020, RPL26, RPL3, } \\
\text { RPL10, RPL36, RPL37, RPS5 }\end{array}$ \\
\hline mmu04510, Focal adhesion & 15 & $3.76 \times 10^{-4}$ & $\begin{array}{l}\text { PDGFB, COL3A1, COL2A1, COL5A3, FLNA, } \\
\text { CCND1, COL1A2, PDGFRB, THBS1, SPP1, etc. }\end{array}$ \\
\hline mmu00670, One carbon pool by folate & 4 & $6.69 \times 10^{-3}$ & SHMT2, ATIC, MTHFD1L, GART \\
\hline mmu00100, Steroid biosynthesis & 4 & $7.98 \times 10^{-3}$ & CYP51, SQLE, LSS, DHCR24 \\
\hline mmu04512, ECM-receptor interaction & 7 & $1.69 \times 10^{-2}$ & $\begin{array}{l}\text { COL3A1, COL1A2, COL6A1, COL2A1, THBS1, } \\
\text { COL5A3, SPP1 }\end{array}$ \\
\hline
\end{tabular}

B, Upregulated genes

\begin{tabular}{|c|c|c|c|}
\hline Term & Count & P-value & Gene name \\
\hline mmu04115, p53 signaling pathway & 11 & $3.09 \times 10^{-8}$ & $\begin{array}{l}\text { CDKN1A, CASP3, ZMAT3, MDM2, PMAIP1, FAS, } \\
\text { APAF1, SESN2, CCNG1, CCNG2, etc. }\end{array}$ \\
\hline mmu04623, Cytosolic DNA-sensing pathway & 7 & $1.10 \times 10^{-4}$ & $\begin{array}{l}\text { DDX58, TMEM173, IL18, RIPK3, NFKBIA, CHUK, } \\
\text { CXCL10 }\end{array}$ \\
\hline mmu05200, Pathways in cancer & 13 & $1.74 \times 10^{-3}$ & $\begin{array}{l}\text { NFKBIA, TCF7L1, FZD6, CTNNA2, CASP3, } \\
\text { CDKN1A, RASSF1, MDM2, WNT9A, FAS, etc. }\end{array}$ \\
\hline $\begin{array}{l}\text { mmu04622, RIG-I-like receptor signaling } \\
\text { pathway }\end{array}$ & 6 & $2.57 \times 10^{-3}$ & $\begin{array}{l}\text { DDX58, TMEM173, ATG12, NFKBIA, CHUK, } \\
\text { CXCL10 }\end{array}$ \\
\hline mmu04210, Apoptosis & 6 & $7.41 \times 10^{-3}$ & CASP3, TNFRSF10B, NFKBIA, FAS, APAF1, CHUK \\
\hline $\begin{array}{l}\text { mmu04621, NOD-like receptor signaling } \\
\text { pathway }\end{array}$ & 5 & $1.11 \times 10^{-2}$ & NOD1, IL18, NFKBIA, TAB2, CHUK \\
\hline mmu04920, Adipocytokine signaling pathway & 5 & $1.44 \times 10^{-2}$ & CPT1C, NFKBIE, NFKBIA, JAK2, CHUK \\
\hline mmu04142, Lysosome & 6 & $2.59 \times 10^{-2}$ & SGSH, ABCB9, AP3M2, IGF2R, SORT1, CTSF \\
\hline mmu05215, Prostate cancer & 5 & $3.77 \times 10^{-2}$ & CDKN1A, MDM2, NFKBIA, TCF7L1, CHUK \\
\hline
\end{tabular}

proliferation of various cell types through several signaling pathways, such as PI3K/Akt (21-23). It has been demonstrated that IGF1 could counteract cisplatin-induced DNA damage by inhibiting cisplatin-induced phosphorylation of histone $\mathrm{H} 2 \mathrm{AX}$ and ataxia-telangiectasia mutated, and blocking DNA double-strand break repair (24). IGFBP5 overexpression and IGF1R inhibition are associated with increased cisplatin sensitivity in esophageal carcinoma cells, lung and ovarian cancer cells (25-27). The present study demonstrated that, compared with cisplatin alone, Tet treatment increased the expression of IGF1, but not IGFBP5. These results suggested that Tet protected HEI-OC1 auditory cells from cisplatin-induced cytotoxicity by restoring IGF1 signaling.

Exposure to cisplatin upregulated genes that were associated with apoptosis and autophagy, including ATG12, ZMAT3, PMAIP1, TRP53INP1 and PIDD1. However, the expression of these genes was not modulated by Tet treatment. By contrast, treatment with Tet downregulated
FOXO3 (significantly) and BBC3 (insignificantly), compared with cisplatin alone. A previous study demonstrated that the proapoptotic FoxO signaling pathway was activated by amikacin-induced ototoxicity (28). FOXO3 mediates a chemo-protection effect in advanced cancer by interacting with TP53 and mutations in TP53 prevent FOXO3 binding, thereby enhancing FOXO3-induced cell death in high-stage neuroblastoma (29). Additionally, FOXO3 links autophagy and apoptosis by regulating the transactivation of the proapoptotic gene BBC3 (30). Under the condition of autophagy inhibition, BBC3 is transactivated by FOXO3 $(29,30)$. In the present study, the expression of $\mathrm{FOXO} 3$ and $\mathrm{BBC} 3$ following cisplatin exposure was increased, consistent with increased apoptosis. It could be hypothesized that increased FOXO3 and BB3-mediated apoptosis may be associated with inhibition of autophagy following cisplatin treatment. Moreover, the protective effect of Tet treatment might be mediated by modulation of autophagy. 
The proapoptotic p53 signaling pathway is activated in the cochlea and in HEI-OC1 auditory cells following cisplatin exposure $(8,10,31,32)$. Xiong et al (32) and Ma et al (31) indicated that the expression or acetylation of p53 in HEI-OC1 auditory cells could be increased by cisplatin treatment, thereby promoting apoptosis. In particular, Ma et al (31) demonstrated that ginkgolide $\mathrm{B}$ prevented cisplatin-induced cytotoxicity and decreased p53 expression in cisplatin-treated cochlear cells. Moreover, Benkafadar et al (33) suggested that the knockdown of p53 could attenuate cisplatin-induced ototoxicity and cochlear cell apoptosis. Consistent with these previous reports, the present study demonstrated that cisplatin induced significant upregulation of p53 signaling-related genes, including ZMAT3, PMAIP1, TRP53INP1 and PIDD1. However, the expression of these genes was not affected by Tet treatment, indicating that the protective effect of Tet on HEI-OC1 auditory cells did not involve p53 signaling.

A previous study suggested that the Wnt signaling pathway protects against neomycin-induced hair cell damage (9). Liu et al (9) demonstrated that $\beta$-catenin activation prevented apoptosis of hair cells. By contrast, inhibition of $\beta$-catenin increased FOXO3 expression, ROS production, and apoptosis in these cells (9). In addition, the inhibition of Wnt signaling in spiral ganglion neurons may increase the levels of ROS (8). The present study suggested that Tet addition into HEI-OC1 auditory cells increased the expression of two mediators of the Wnt signaling pathway, including TCF7L1 and FZD6. Thus, activation of Wnt signaling may be involved in the Tet-mediated protective effect on HEI-OC1 auditory cells. However, this study demonstrated that WNT2 and WNT4 genes, which are necessary for the activation of FZD6, were downregulated specifically by combination with Tet. These results suggested that the activation of Wnt signaling may be mediated by novel factors, rather than WNT2/4.

The present study has limitations. Firstly, the concentrations of cisplatin used in this study were too low. To minimize its cytotoxicity in vitro, cells were treated with cisplatin and Tet at concentrations $<\mathrm{IC}_{50}$ values. Obvious reverse changes in cell viability and genomics were observed between combination treatment of $37.5 \mathrm{mg} / \mathrm{l}$ Tet and $30 \mu \mathrm{M}$ cisplatin, and $30 \mu \mathrm{M}$ cisplatin alone. Moreover, the potential mechanisms underlying the role of Tet were only identified using RNA-seq and bioinformatics analysis. Experimental validation would provide further insight into the molecular basis of Tet-mediated inhibition of ototoxicity.

In conclusion, the present study confirmed that low doses of Tet could attenuate cisplatin-induced cytotoxicity in HEI-OC1 auditory cells. Gene expression analysis suggested that cisplatin induced ototoxicity in vitro by activating the p53 and FoxO signaling pathways, and inhibiting IGF signaling. Tet attenuated ototoxicity through activation of the $\mathrm{Wnt} / \beta$-catenin and IGF pathways, and inhibition of FOXO3/BBC3 signaling. Further validation is required to directly demonstrate the roles of these pathways in auditory cells.

\section{Acknowledgements}

The authors would like to thank Professor Federico Kalinec (David Geffen School of Medicine at UCLA, CA, USA) for the generous donation of the HEI-OC1 auditory cells.

\section{Funding}

No funding was received.

\section{Availability of data and materials}

All data generated or analyzed during this study are included in this published article. The fastq files of raw sequencing data are available from the corresponding author upon reasonable request.

\section{Authors' contributions}

GG and XT designed the study. GG, XH, JC and LB acquired, analyzed and interpreted the data. XH, JC and LB carried out the statistical analysis.GG drafted the manuscript. XH and XT revised the manuscript for important intellectual content. All authors read and approved the final manuscript.

\section{Ethics approval and consent to participate}

Not applicable.

\section{Patient consent for publication}

Not applicable.

\section{Competing interests}

The authors declare that they have no competing interests.

\section{References}

1. Breglio AM, Rusheen AE, Shide ED, Fernandez KA, Spielbauer KK, McLachlin KM, Hall MD, Amable L and Cunningham LL: Cisplatin is retained in the cochlea indefinitely following chemotherapy. Nat Commun 8: 1654, 2017.

2. Shorter P, Harden F, Owen R, Panizza B, Burmeister B, Sommerville J, Mengersen K and Foote M: Risk profiles for sensorineural hearing loss in patients with head and neck cancer receiving cisplatin-based chemoradiation. J Med Imaging Radiat Sci 48: 61-67, 2017.

3. Wang J, Chen YY, Tai A, Chen XL, Huang SM, Yang C, Bao Y, Li NW, Deng XW, Zhao C, et al: Sensorineural hearing loss after combined intensity modulated radiation therapy and cisplatin-based chemotherapy for nasopharyngeal carcinoma. Transl Oncol 8: 456-462, 2015.

4. Robertson MS, Hayashi SS, Camet ML, Trinkaus K, Henry J and Hayashi RJ: Asymmetric sensorineural hearing loss is a risk factor for late-onset hearing loss in pediatric cancer survivors following cisplatin treatment. Pediatr Blood Cancer 66: e27494, 2019.

5. Bass JK, Hua CH, Huang J, Onar-Thomas A, Ness KK, Jones S, White S, Bhagat SP, Chang KW and Merchant TE: Hearing loss in patients who received cranial radiation therapy for childhood cancer. J Clin Oncol 34: 1248-1255, 2016.

6. Wu X, Li X, Song Y, Li H, Bai X, Liu W, Han Y, Xu L, Li J, Zhang D, et al: Allicin protects auditory hair cells and spiral ganglion neurons from cisplatin-Induced apoptosis. Neuropharmacology 116: 429-440, 2017.

7. Sheth S, Mukherjea D, Rybak LP and Ramkumar V: Mechanisms of cisplatin-induced ototoxicity and otoprotection. Front Cell Neurosci 11: 338, 2017.

8. Liu W, Xu X, Fan Z, Sun G, Han Y, Zhang D, Xu L, Wang M, Wang X, Zhang S, et al: Wnt signaling activates TP53-induced glycolysis and apoptosis regulator and protects against cisplatin-induced spiral ganglion neuron damage in the mouse cochlea. Antioxid Redox Signal 30: 1389-1410, 2019.

9. Liu L, Chen Y, Qi J, Zhang Y, He Y, Ni W, Li W, Zhang S, Sun S, Taketo MM, et al: Wnt activation protects against neomycin-induced hair cell damage in the mouse cochlea. Cell Death Dis 7: e2136,2016. 
10. Guo X, Bai X, Li L, Li J and Wang H: Forskolin protects against cisplatin-induced ototoxicity by inhibiting apoptosis and ROS production. Biomed Pharmacother 99: 530-536, 2018.

11. Zhang Q, Liu H, McGee J, Walsh EJ, Soukup GA and He DZ: Identifying microRNAs involved in degeneration of the organ of corti during age-related hearing loss. PLoS One 8: e62786, 2013.

12. Wang P, Zhang P, Huang J, Li M and Chen X: Trichostatin a protects against cisplatin-induced ototoxicity by regulating expression of genes related to apoptosis and synaptic function. Neurotoxicology 37: 51-62, 2013.

13. Bhatta P, Dhukhwa A, Sheehan K, Al Aameri RFH, Borse V, Ghosh S, Sheth S, Mamillapalli C, Rybak L, Ramkumar V and Mukherjea D: Capsaicin protects against cisplatin ototoxicity by changing the STAT3/STAT1 ratio and activating Cannabinoid (CB2) receptors in the Cochlea. Sci Rep 9: 4131, 2019.

14. Kitcher SR, Kirkwood NK, Camci ED, Wu P, Gibson RM, Redila VA, Simon JA, Rubel EW, Raible DW, Richardson GP and Kros CJ: ORC-13661 protects sensory hair cells from aminoglycoside and cisplatin ototoxicity. JCI Insight 4: e126764, 2019.

15. Cui C, Liu D and Qin X: Attenuation of streptomycin ototoxicity by tetramethylpyrazine in guinea pig cochlea. Otolaryngol Head Neck Surg 152: 904-911, 2015.

16. Du S, Yao Q, Tan P, Xie G, Ren C, Sun Q, Zhang X, Zheng R, Yang K, Yuan Y and Yuan Q: Protective effect of tanshinone IIA against radiation-induced ototoxicity in HEI-OC1 cells. Oncol Lett 6: 901-906, 2013.

17. Bayram A, Kaya A, Akay E, Hira İ and Özcan I: The protective role of tetramethylpyrazine against cisplatin-induced ototoxicity. Int J Pediatr Otorhinolaryngol 94: 1-7, 2017.

18. Hou LL, Xu QJ, Hu GQ and Xie SQ: Synergistic antitumor effects of tanshinone II A in combination with cisplatin via apoptosis in the prostate cancer cells. Yao Xue Xue Bao 48: 675-679, 2013 (In Chinese)

19. Chang TW, Lin CY, Tzeng YJ and Lur HS: Synergistic combinations of tanshinone IIA and trans-resveratrol toward cisplatin-comparable cytotoxicity in HepG2 human hepatocellular carcinoma cells. Anticancer Res 34: 5473-5480, 2014.

20. Banday AR, Baumgartner M, Al Seesi S, Karunakaran DK, Venkatesh A, Congdon S, Lemoine C, Kilcollins AM, Mandoiu I, Punzo $\mathrm{C}$ and Kanadia RN: Replication-dependent histone genes are actively transcribed in differentiating and aging retinal neurons. Cell Cycle 13: 2526-2541, 2014.

21. KadriZ,Lefevre C, Goupille O, Penglong T, Granger-Locatelli M, Fucharoen S, Maouche-Chretien L, Leboulch P and Chretien S: Erythropoietin and IGF-1 signaling synchronize cell proliferation and maturation during erythropoiesis. Genes Dev 29: 2603-2616, 2015

22. Yu M, Wang H, Xu Y, Yu D, Li D, Liu X and Du W: Insulin-like growth factor-1 (IGF-1) promotes myoblast proliferation and skeletal muscle growth of embryonic chickens via the PI3K/Akt signalling pathway. Cell Biol Int 39: 910-922, 2015.
23. Bruchim I, Attias $\mathrm{Z}$ and Werner H: Targeting the IGF1 axis in cancer proliferation. Expert Opin Ther Targets 3: 1179-1192, 2009.

24. Jeon JH, Kim SK, Kim HJ, Chang J, Ahn CM and Chang YS: Insulin-like growth factor-1 attenuates cisplatin-induced gammaH2AX formation and DNA double-strand breaks repair pathway in non-small cell lung cancer. Cancer Lett 272: 232-241, 2008.

25. Du J, Shi HR, Ren F, Wang JL, Wu QH, Li X and Zhang RT: Inhibition of the IGF signaling pathway reverses cisplatin resistance in ovarian cancer cells. BMC Cancer 17: 851, 2017.

26. Sun Y, Zheng S, Torossian A, Speirs CK, Schleicher S, Giacalone NJ, Carbone DP, Zhao Z and Lu B: Role of insulin-like growth factor-1 signaling pathway in cisplatin-resistant lung cancer cells. Int J Radiat Oncol Biol Phys 82: e563-e572, 2012.

27. Chan D, Zhou Y, Chui CH, Lam KH, Law S, Chan AS, Li X, Lam AK and Tang JCO: Expression of insulin-like growth factor binding protein-5 (IGFBP5) reverses cisplatin-resistance in esophageal carcinoma. Cells 7: 143, 2018

28. Liu S, Zhang X, Sun M, Xu T and Wang A: FoxO3a plays a key role in the protective effects of pomegranate peel extract against amikacin-induced ototoxicity. Int J Mol Med 40: 175-181, 2017.

29. Rupp M,Hagenbuchner J, Rass B, FieglH, Kiechl-Kohlendorfer U, Obexer $\mathrm{P}$ and Ausserlechner MJ: FOXO3-mediated chemo-protection in high-stage neuroblastoma depends on wild-type TP53 and SESN3. Oncogene 36: 6190-6203, 2017.

30. Fitzwalter BE and Thorburn A: FOXO3 links autophagy to apoptosis. Autophagy 14: 1467-1468, 2018.

31. Ma W, Li J, Hu J, Cheng Y, Wang J, Zhang X and Xu M: MiR214-regulated p53-NOX4/p66shc pathway plays a crucial role in the protective effect of Ginkgolide B against cisplatin-induced cytotoxicity in HEI-OC1 cells. Chem Biol Interact 245: 72-81, 2016.

32. Xiong H, Pang J, Yang H, Dai M, Liu Y, Ou Y, Huang Q, Chen S, Zhang Z, Xu Y, et al: Activation of miR-34a/SIRT1/p53 signaling contributes to cochlear hair cell apoptosis: Implications for age-related hearing loss. Neurobiol Aging 36: 1692-1701, 2015.

33. Benkafadar N, Menardo J, Bourien J, Nouvian R, François F, Decaudin D, Maiorano D, Puel JL and Wang J: Reversible p53 inhibition prevents cisplatin ototoxicity without blocking chemotherapeutic efficacy. EMBO Mol Med 9: 7-26, 2017.

This work is licensed under a Creative Commons Attribution-NonCommercial-NoDerivatives 4.0 International (CC BY-NC-ND 4.0) License. 